\title{
Time Series-, Time-Frequency- and Spectral Analyses of Sensor Measurements in an Offshore Wave Energy Converter Based on Linear Generator Technology
}

\author{
Erland Strömstedt, Andrej Savin, Olle Svensson, Mats Leijon \\ The Swedish Centre for Renewable Electric Energy Conversion, Division for Electricity, \\ Department of Engineering Sciences, Uppsala University, Uppsala, Sweden \\ Email: erland.stromstedt@angstrom.uu.se
}

Received August 20, 2012; revised September 24, 2012; accepted October 10, 2012

\begin{abstract}
Inside the second experimental wave energy converter (WEC) launched at the Lysekil research site on the Swedish west coast in March 2009 a number of sensor systems were installed for measuring the mechanical performance of the WEC and its mechanical subsystems. One of the measurement systems was a set-up of 7 laser triangulation sensors for measuring relative displacement of the piston rod mechanical lead-through transmission in the direct drive. Two measurement periods, separated by 2.5 month, are presented in this paper. One measurement is made two weeks after launch and another 3 months after launch. Comparisons and correlations are made between different sensors measuring simultaneously. Noise levels are investigated. Filtering is discussed for further refinement of the laser triangulation sensor signals in order to separate noise from actual physical displacement and vibration. Measurements are presented from the relative displacement of the piston rod mechanical lead-through, from magnetic flux in the air gap, mechanical strain in the WEC structure, translator position and piston rod axial displacement and active AC power. Investigation into the measurements in the time domain with close-ups, in the frequency domain with Fast Fourier transform (FFT) and with time-frequency analysis with short time Fourier transform (STFT) is carried out to map the spectral content in the measurements. End stop impact is clearly visible in the time-frequency analysis. The FFT magnitude spectra are investigated for identifying the cogging bandwidth among other vibrations. Generator cogging, fluctuations in the damping force and in the Lorenz forces in the stator are distinguished and varies depending on translator speed. Vibrations from cogging seem to be present in the early measurement period while not so prominent in the late measurement period. Vibration frequencies due to wear are recognized by comparing with the noise at generator standstill and the vibration sources in the generator. It is concluded that a moving average is a sufficient filter in the time domain for further analysis of the relative displacement of the piston rod mechanical lead-through transmission.
\end{abstract}

Keywords: Wave Power; Wave Energy Converter; Linear Generator; Sensor Measurements; Spectral Analysis; Cogging; Filtering; Laser Triangulation Sensor; Draw-Wire Sensor; Force Transducer; Strain Gauges; Search Coil; Power Generation

\section{Introduction}

For the past decade, the Swedish Centre for Renewable Electric Energy Conversion at Uppsala University, Sweden, has been working on wave energy system, consisting of a point absorber with a surface-floating buoy and an encapsulated permanent magnet linear generator on the seabed. The Uppsala project is one of many past and present wave energy projects around the world, with very different technical approaches. A few of the other projects and technologies are described in [1-5].

During operation an offshore WEC has to sustain millions of cyclical sequences of varying static, dynamic and potentially very high mechanical loads at sea. For a com- plete understanding of a wave energy converter device it is important to know how the device operates in the water, how the motion of the waves affects the electrical and mechanical subsystems, how this motion can be measured and how to interpret the information in the measured data. Only a few full scale experimental studies have been presented so far with sensor measurements inside WECs in operation at sea, summarized in Lindroth et al. [6]. The magnitude and character of the motion has impact on engineering issues and optimization of control parameters, as well as theoretical understanding of the system in order to come up with durable designs for long term sustainability. 
In this paper experimental data from different measurement systems in the second WEC prototype at the Lysekil Research Site (LRS) are studied and compared in the time and frequency domain. A post-measurement time-frequency analysis based on STFT and frequency analysis based on FFT is carried out to map the spectral content in the measurements inside the WEC during intervals with two narrow sea states with 2.5 month separation.

The purpose of the work is to 1) present the spectral content of the laser sensor measuring systems inside the WEC , 2) to make comparisons in both the time and frequency domain with output from other sensors to identify typical vibrations, mainly cogging and end stop impact, and 3) reflections on finding a suitable filter for refining the laser sensor measurements in the time domain.

In Section 2, the background of the Lysekil project is presented and described along with the WEC in focus for the study. Section 3 deals with the theoretical model used for the spectral analysis and sources of vibration along with assumptions made. The experimental set-up of the sensor measuring systems and details of the measurements are then presented in Section 4. Finally, in Sections 5 and 6 the measurement data and achieved results are put forward and discussed.

\section{Background}

The experimental work presented in this paper was performed at the Lysekil Research Site (LRS) off the Swedish west coast. LRS is located about $10 \mathrm{~km}$ southsouthwest of the town of Lysekil, between a northern $\left(58^{\circ} 11^{\prime} 850 \mathrm{~N} 11^{\circ} 22^{\prime} 460 \mathrm{E}\right)$ and a southern marker

$\left(58^{\circ} 11^{\prime} 630 \mathrm{~N} 11^{\circ} 22^{\prime} 460 \mathrm{E}\right)$; see Figure 1. The LRS was established in 2004 for the purpose of studying full-scale devices of the selected wave energy conversion system under development at Uppsala University. The wave climate is moderate with a typical average energy flux of $3.4 \mathrm{~kW} / \mathrm{m}$. From an evaluation point of view the LRS serves the purpose with regard to wave height of an otherwise scalable WEC system $[7,8]$. The site has a water depth of about $25 \mathrm{~m}$ and a flat sandy bottom. It is connected electrically to the small island of Gullholmen through a $3 \mathrm{~km}$ long sea cable. More details about the LRS can be found in [7].

Three different complete wave energy converter prototypes, named L1, L2 and L3, an underwater substation [9], an observation tower [10], a wave measurement buoy [11] and around 8 biology buoys, for environmental studies $[12,13]$, were operating in the LRS at the time of the experiment. The data in this paper comes from measurements on L2 during the first wave power park experiments in during the period from the 15th of May until the 23rd of September. Figure 2(b) shows a photo of

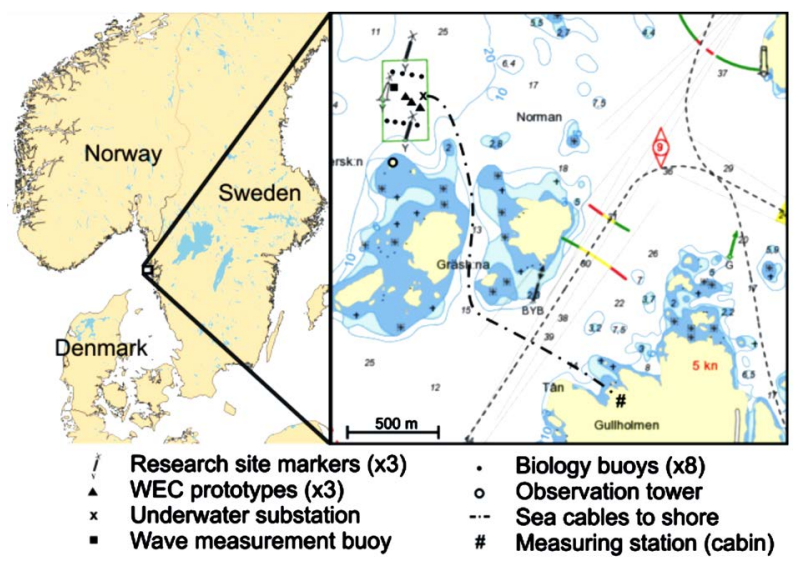

Figure 1. The Lysekil research site during the experiments in 2009.

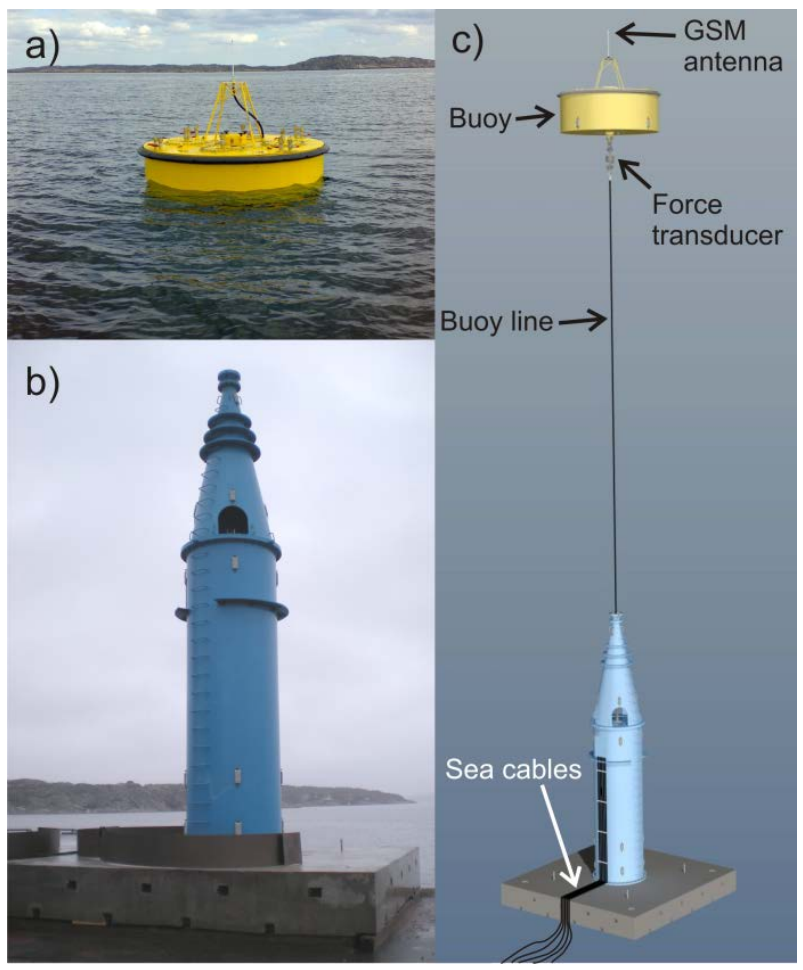

Figure 2. (a) The buoy attached to L2 after launch; (b) WEC L2 on cay before launch; (c) CAD assembly of L2 to scale at $25 \mathrm{~m}$ depth.

WEC L2 before deployment and Figure 2(a) of the buoy at the LRS just after launch. Figure 2(c) shows a CAD assembly image to scale of the WEC deployed at 25 meters depth with the buoy at the surface. The force transducer measuring system is indicated.

The internal layout of the WEC is shown in Figure 3. As a wave passes, the buoy is lifted, and this motion is transferred to the generator. 37 rows of permanent Neodymium Iron Boron $\left(\mathrm{Nd}_{2} \mathrm{Fe}_{14} \mathrm{~B}\right)$ magnets with the pole width of $50 \mathrm{~mm}$ are mounted on the translator and the 


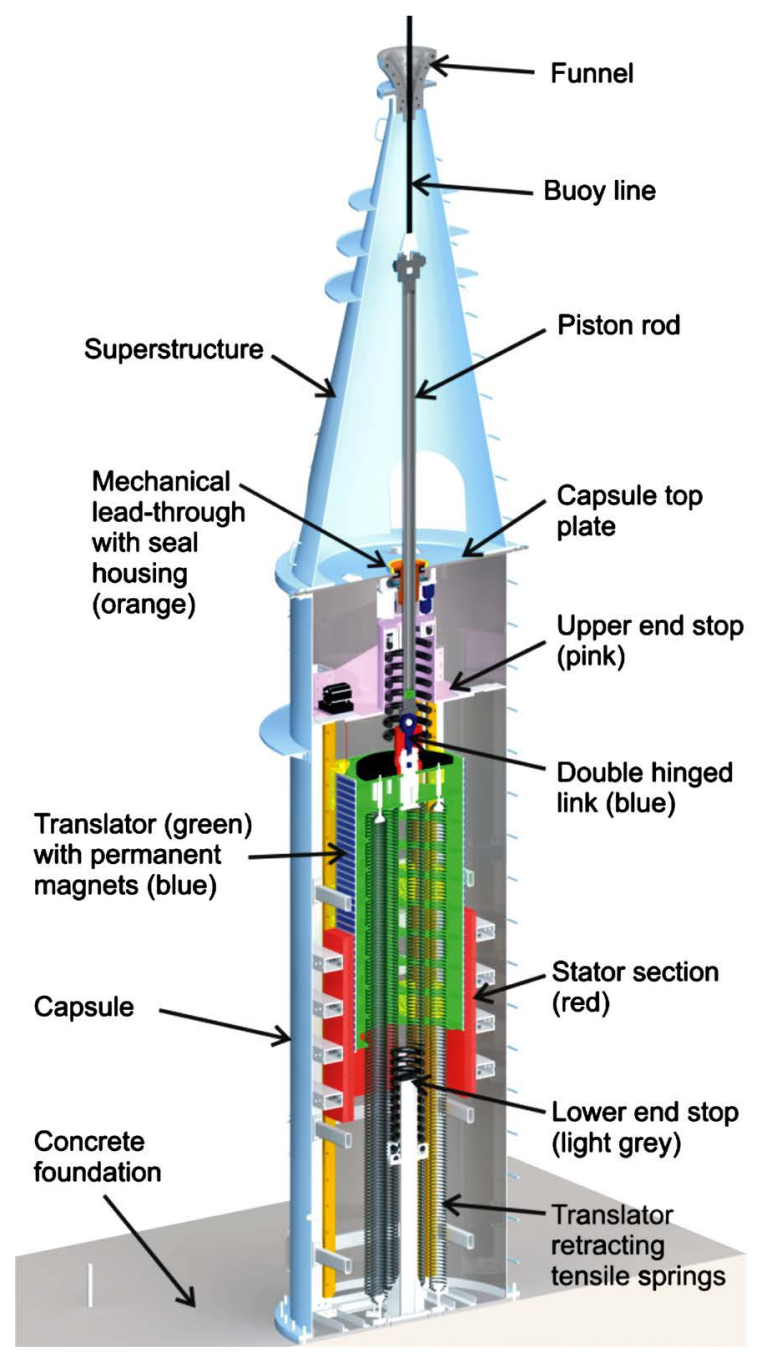

Figure 3. Cross-sectional view of a CAD assembly of $\mathrm{L2}$ with functional parts indicated.

relative motion between these and the stator induces voltage in the stator windings. At a translator speed of $0.67 \mathrm{~m} / \mathrm{s}$ the generator produces $10 \mathrm{~kW}$ at a line-to-line voltage of $200 \mathrm{~V}$ when connected to a nominal load of 4 $\Omega$ and an air gap of approx. $2.5 \mathrm{~mm}$. The efficiency of the generator in this case is $86 \%$ [7]. Further generator parameters are described in $[14,15]$.

There are 8 tensile springs mounted between the bottom of L2 and high up inside the translator framework. The springs pull down the translator when the buoy is in a wave trough. There are also end stops with compression springs to prevent the translator from slamming into the capsule bottom and top plate. The free stroke length is $1.79 \mathrm{~m}$. It can then move another additional $0.243 \mathrm{~m}$ at the top and $0.200 \mathrm{~m}$ at the bottom. While compressing the end stop springs, making the full possible stroke length $2.21 \mathrm{~m}$.

The buoy line is guided by a funnel at the top of a flooded superstructure. A piston rod transfers the me- chanical force from the guided buoy line in to the generator through a seal housing in a mechanical leadthrough device; see Figure 4. The seal housing is mounted on a $\mathrm{C}$-shaped rubber gasket at the centre opening in the capsule top plate. The seal housing flange is clamped around the gasket by two large hook nuts screwed on to the outside of the seal housing inside the capsule; see Figure 4. A dynamic sealing system inside the seal housing keeps the capsule watertight as the piston rod reciprocates with the translator without rotating.

A double hinged link between the piston rod and translator enables the lower rod end to move sideways. The

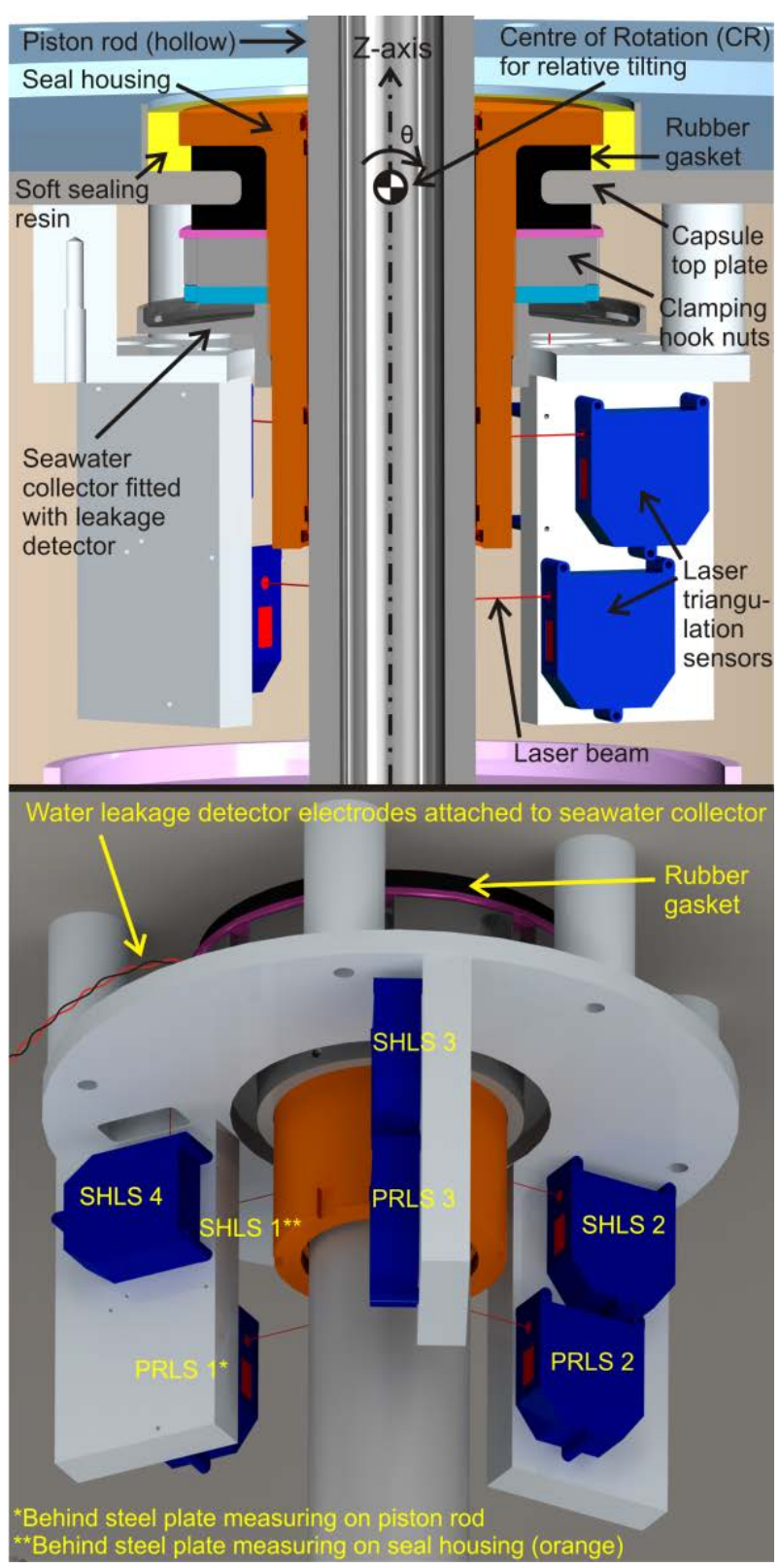

Figure 4. Piston Rod Laser Sensors (PRLS) 1 - 3 and Seal Housing Laser Sensor (SHLS) 1 - 4 with rigid sensor set-up rig attached to the capsule top plate. 
centre of rotation for the tilting of the piston rod and seal housing is thereby maintained inside the seal housing at level with the top plate middle layer. The capsule is pressurized with nitrogen gas to equal the pressure of the outside seawater at the level of the capsule bottom plate. Several papers have been published on the Lysekil project, e.g. regarding energy potential [16], force measurements [17-19], power absorption [20-22], farm layout [23], electrical control [24].

The subject of studying WECs in the frequency domain is not uncommon. Earlier research has for example investigated numerical and experimental modelling aspects [25], wave spectra for performance assessment [26] and assessing dynamic effects relevant for wear in hydraulic direct drives [27]. A study of the spectral content in the measurements from inside L2 at the LRS may add to the understanding of the mechanical performance in the WEC and how the measured data is to be interpreted for further analysis of the piston rod mechanical leadthrough transmission.

\section{Experimental Set-Up}

\subsection{Sensors and Measurements on L2}

The sensors inside WEC L2 measure: translator position and piston rod outside length, air temperature, humidity, water leakage, water level, stator temperature, magnetic flux in the air-gap between stator and translator, relative sideway displacement (i.e. lateral movements) of the piston rod and its matching seal housing in the mechanical lead-through transmission, strain in the inner mechanical framework and bending strain in the generator capsule [28].

This paper focuses on sensors in L2 which measure the relative displacement in of the piston rod mechanical lead-through transmission and which may be influenced by mechanical vibrations. Temperature, humidity, water detection and water level are therefore excluded. The laser triangulation sensor measurements on the piston rod and seal housing are compared within the time and frequency domain with added measurements of cogging frequency, active AC power, magnetic flux in the air gap, mechanical strain in the WEC structure and measurements of piston rod axial displacement and translator position. The force transducer measuring axial force in the buoy line from underneath the buoy is also included, even though it measures with $16 \mathrm{~Hz}$ and uses another data acquisition system communicating through the GSM network.

The analogue output from the sensors inside the WEC was signal-conditioned in the WEC and sent through a 70 $\mathrm{m}$ twisted pair cable to the substation where it was simultaneously sampled by a programmable automation controller (PAC) on all channels at $256 \mathrm{~Hz}$ with a com-
pactRio system from National instruments [29]. The digitized data was then transferred $3 \mathrm{~km}$ with a pointto-point copper link from the substation to the onshore measuring station, where it was stored on a hard disk drive. All the measuring systems, excluding the force transducer, communicate through the data acquisition system in the sea cables described in [29,30]; see Figures 1 and 2 .

A brief description will now follow of the individual sensor measuring systems involved in the study.

A. Laser triangulation sensors. A set-up of 7 laser triangulation sensors from Micro Epsilon, model optoNCDT 1700-20, have been installed to measure the relative sideway displacements of the piston rod and seal housing in the piston rod mechanical lead-through transmission in WEC L2; see Figures 4 and 5.

The laser sensors are rigidly mounted onto a rigid sensor set-up rig surrounding the mechanical lead-through underneath the capsule top plate. Each stationary sensor measures linear displacement with a diode laser beaming a spot onto the moving target surface and detecting diffuse reflection with optics and a CCD array. The sensors are mounted with fixed angular, radial and vertical positions relative to each other. The laser sensor measurement system has been system calibrated (end-to-endcalibrated) for good accuracy.

Each sensor measures relative displacement within a measuring range of $\pm 10 \mathrm{~mm}$ at a working distance of 50 $\mathrm{mm}$. with an accuracy estimated to be in the order of the sensor non-linearity of due to the very accurate system calibration method and relative aspect of measuring, as presented in Strömstedt et al. [30].

Piston Rod Laser Sensors (PRLS) 1 - 3 measures the relative displacement of the piston rod by beaming horizontally and radially in towards the moving target surface of the piston rod with a 120 degree angular separation. Seal Housing Laser Sensors (SHLS) 1 - 3 measures the same way towards the moving target surface of the seal housing and are mounted $96 \mathrm{~mm}$ higher up. SHLS 4 measures the vertical motion of the seal housing by beaming a laser toward the bottom target surface of a seawater collector plate used for detecting if any leakage occurs through the rubber gasket. The seawater collector
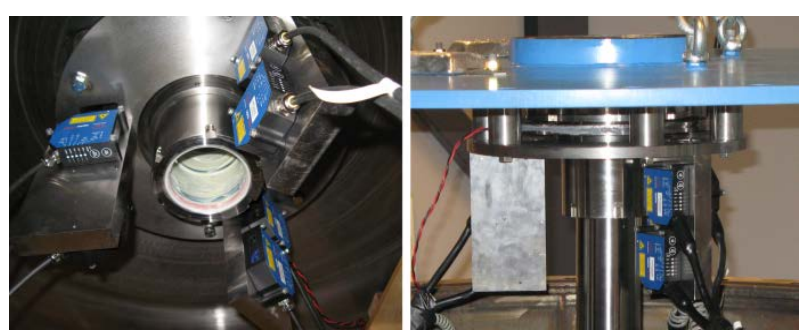

Figure 5. The laser triangulation sensor set-up rig surrounding the piston rod mechanical lead-through in $\mathrm{L2}$. 
is rigidly mounted to the outside of the seal housing above rigid the laser sensor set-up rig.

The sensor output is amplified by a factor of 2.8 inside the WEC and damped by a factor of 0.5 in the substation to fit the input swing of the sampling PAC in the data acquisition system. An in-depth presentation of the entire laser triangulation sensor measuring system, choice of sensor, geometrical set-up of sensors, sensor adaptation, configuration, mounting, system calibration and accuracy, noise analysis, among other things, is described in Strömstedt et al. [30]

B. Draw-wire sensor. A draw-wire sensor has been installed to measure the vertical translator position and the axial displacement and position of the piston rod. The draw-wire sensor is a standard wire sensor from Micro Epsilon, WDS-3000-P115-SA-P-E. The sensor is attached to the top side of the upper end stop plate of the inner mechanical framework; see Figures 2, 6 and 7. A hole is drilled through the upper end stop for the wire which is fastened to the top of the translator; see Figure 6. The sensor is protected from large vibrations by the use of a rubber damper. An in-depth presentation of the entire draw-wire sensor measuring system including calibration, accuracy and noise analysis was presented in Strömstedt et al. [30].

C. Strain gauges. WEC L2 was provided with strain

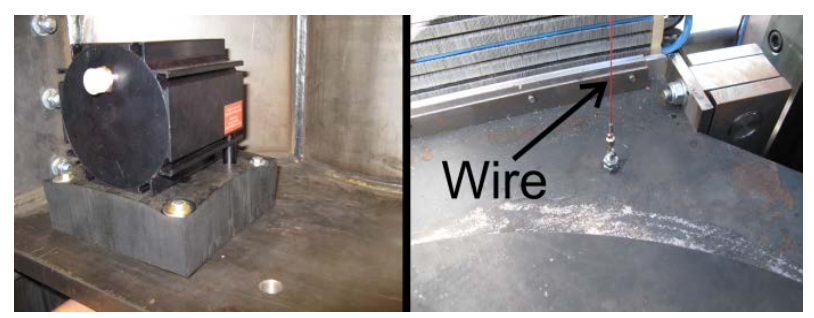

Figure 6. The draw-wire sensor on top of the upper end stop and the attachment of the wire to the top of the translator.

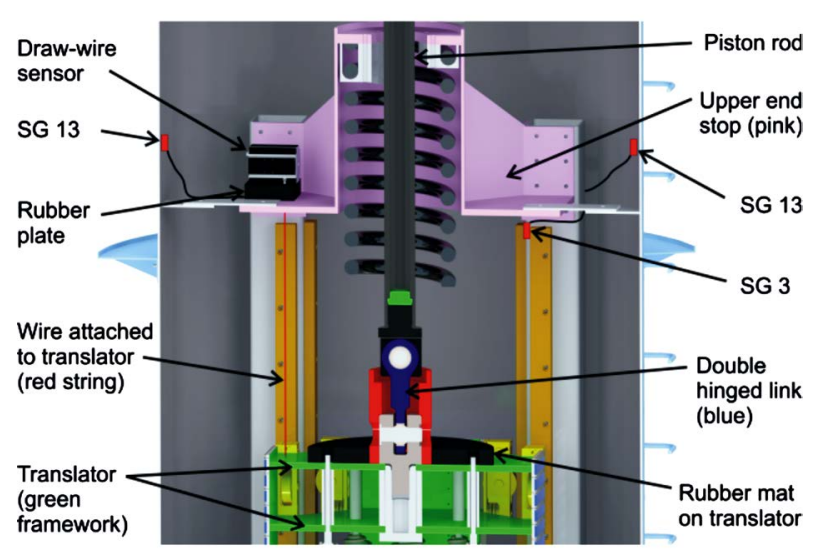

Figure 7. The positions of the draw-wire sensor, the strain gauges SG3 and SG13, and other important parts close by the upper end stop and at the top of the translator in $\mathrm{L} 2$. gauge circuits for measuring bending strain on the capsule wall and for measuring uni-axial strain in the inner framework structure. In this paper two of the eleven strain gauge circuits (SG) are singled out to represent the typical strain gauge signal content in the inner and outer WEC structure.

SG 13 is a 2-active-gauge system for bending strain measurement with two resistive strain gauges from Kyowa, KFN-5-350-C9-16, mounted inside the capsule on opposite sides with a separation of $180^{\circ}$; see Figures 7 and 8. SG 3 is a strain gauge circuit of an activedummy 2-gauge system mounted on the corner pillar of the inner framework close to the upper end stop; see Figures 7 and 8.

When the WEC is under working load and the translator moves up and down stress occurs in the capsule and inner framework structure. The strain gage amplifying electronics has two major design parts. The first one is the discrete amplifier placed close to the strain element amplifying the differential signal from the measurement bridge.

This signal was sent to an instrument amplifier inside the WEC that increased the gain even more before the signal was transmitted to the substation and sampled by the PAC together with all other measurements.

The set-up of strain gauges in L2, calibration, accuracy, formulas for calculating the strain and measurements have been presented in-depth in Savin et al. [18,19].

D. Search coils. The magnetic flux in the air-gap between stator and translator is measured with a so-called search coil (SC) [31]. A SC is a passive inductive sensor composed of a single coil. It measures the induced electromotive force (EMF) in a closed loop equal to the negative time derivate of the enclosed magnetic flux $(\Phi)$.

The SCs used in L2 is designed on a two layer printed circuit board (PCB) with ten turns on every side. 8 SCs were installed in L2. SC 5 was selected to represent the typical signal measured by the SCs as the translator reciprocates in the generator; see Figure 9. The SC signal is amplified with a factor 20.8 in the WEC and transmitted through the data acquisition system.

SC 5 is positioned in the vertical middle position and closed by the horizontal edge of one of the 4 stator sections; see Figure 9. The search coil design, calibration, set-up in L2, accuracy and time domain measurements

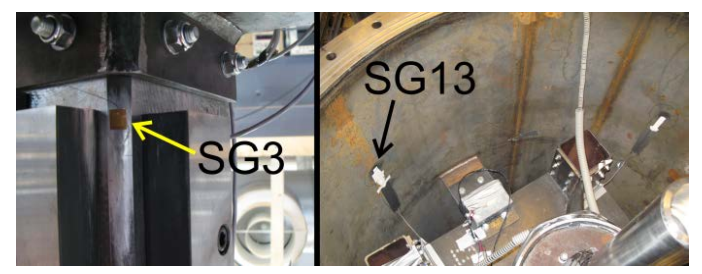

Figure 8. The position and mounting of SG 3 and SG 13 in L2. 


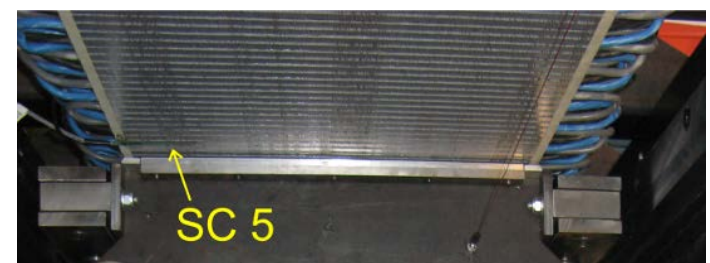

Figure 9. The position of SC 5 in the air gap of one of the 4 stator sections in $\mathbf{L 2}$.

are further described in [28].

E. Force transducer. A force transducer from HBM, U2B $200 \mathrm{kN}$, is used for measuring the axial force in the buoy line with a frequency of $16 \mathrm{~Hz}$; see Figure 10.

The cylindrical buoy attached to L2, weighing 2 tons, with a diameter of $3 \mathrm{~m}$ and a height of $1.2 \mathrm{~m}$ has the force transducer mounted underneath the buoy, between a couple of chain links and the buoy line; see Figure 10. The battery powered transducer is protected by a casing and embedded in a polymer resin for protection. The cables enter the buoy through a watertight rubber hose. The signal is transmitted from an antenna on the buoy through the GSM network with the use of a Mitec-SateLite60 data logger system and stored at the measuring station. Since the buoy is moving relative to the ocean floor, it is difficult to make a cable connection to the substation. The communication of the axial force measurements from underneath the buoy is made through the GSM network and described in [32].

The force transducer measuring system has been described including calibration and accuracy in Savin et al. [18]. The axial force measurements indicate if an end stop impact has occurred. Changes in the axial force may affect the bending of the steel structures in the WEC and cause possible vibrations.

F. Voltage and current measurements. The 3-phase AC voltages from the WEC are measured in the substation, where also the currents are measured with hall current transducers. Active AC power is studied in order to draw conclusions on cogging frequencies. The WEC was connected to $14.1 \Omega$ air cooled DC loads onshore in the May measurements and delta-connected to $12 \Omega$ water cooled dump loads close by the WEC in the August measurements presented in this paper. The loads are per phase. The sampling frequency for the power measurements is $256 \mathrm{~Hz}$ for both measurements periods, which is the same as the sampling frequency for the sensor measurements inside the WEC. The voltage and current measurements are presented in detail in Boström et al. [24, 33].

\section{Theory}

\subsection{Signal Content and Noise}

Inside the WEC the generator is running with a varying

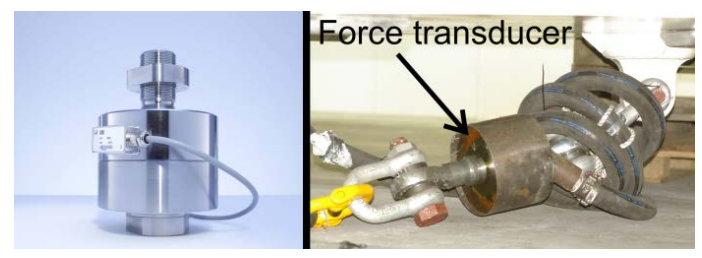

Figure 10. (Left) The force transducer; (Right) The connection underneath the buoy with the force transducer encased and sealed off in a soft polymer resin.

speed following the waves at the surface. In theory the signals from the laser triangulation sensors and the other sensors will be of a non-stationary continuous character:

- Sine components with changing amplitudes and/or changing frequencies, such as the signal content associated with the ripples of cogging and the oscillating motion of the translator following the varying amplitudes and/or frequencies of the waves.

- Random signals with statistical properties changing with time, such as noise and disturbances within the measuring environment and within the measuring system.

- Transients appearing with varying intervals and with varying characteristics in time and frequency, such as the signal content associated with the end stop impacts.

The RMS noise and the signal-to-noise ratio (SNR) for the laser triangulation sensors and the draw wire sensor measurements have been investigated for a typical measurement period in May and August without end stop impact in [30]. A reference case from measurements with the generator at a standstill on the $14^{\text {th }}$ of October is presented in this paper for further information about the noise characteristics.

\subsection{Vibrations from Cogging}

Mechanical vibrations in the WEC may influence sensor output, especially for sensors measuring mechanical entities, such as the laser triangulation sensors measuring the relative motion of the piston rod and the seal housing. Cogging is a source of vibration in the generator. The vibrations may influence the motion of the objects and/or the sensors.

Cogging is the result of fluctuations in the electromagnetic force between the translator magnets and the stator armature in the generator. It has been extensively investigated in linear generators and motors; for example in [34-40]. In conventional rotating permanent magnet generators cogging is mostly referred to the interaction between the edges of the magnets and the stator teeth at the winding slots. At high speed the moment of inertia will however filters out most of the effect of cogging torque in conventional generators. In power production with slow moving permanent magnet linear generators 
many poles are needed to compensate for the lack in rotational speed. The translator moves in and out of the stator instead of rotating inside it. This causes another specific effect relating to cogging.

The most prominent cogging effect occurs when the permanent magnets pass the longitudinal stator outlet ends [40]. At the longitudinal ends of the stator the magnetic field density increase in the stator armature as the magnets starts to slip out of the stator and the magnetic circuit. A field concentration occurs at the edge causing a pulsating attraction force in the air gap with every magnet that passes by. The pulsating force can be separated into a normal and a tangential component. The longitudinal end effect also propagates inwards in the stator affecting the other magnetic circuits and cause electromechanical force ripples throughout the machine. The normal force component attracts the translator towards the translator and has been investigated at no load by Nilsson et al. [39]. The tangential component counteracts the axial force in the buoy line which emanates from the waves pulling the buoy and the translator in the generator. This pulsating cogging force results in vibration. The magnitude of the cogging mainly depends on the geometry and strength of the magnets, the armature geometry and the air gap width [34].

In L2 the translator is $1867 \mathrm{~mm}$ long. The stator is $1264 \mathrm{~mm}$ long. This means that the magnets will always be moving past one of the stator outlet ends during operation. In other words, as long as the translator is moving cogging will occur, however with low frequency towards the end stops and no frequency at end stop standstill. The cogging frequency will vary with the speed of the reciprocating translator as it moves with the varying amplitude and frequency of the ocean waves. The characteristic frequency $\left(f_{\text {cogging }}\right)$ is set by the magnetic pole width $\left(w_{\text {pole }}\right)$ and varies with the speed of the translator ( $v_{\text {translator }}$ ) according to Equation (1),

$$
f_{\text {cogging }}=\frac{v_{\text {translator }}}{w_{\text {pole }}}
$$

Vibrations from cogging may propagate through the WEC structure and the frequencies may be detected in the different sensor measurements. The spectral content from cogging will have a continuous distribution over a certain bandwidth and be repeated over different harmonics. With Equation (1) it is possible to calculate the instantaneous cogging base frequency in the generator and compare it with the spectral content found in the sensor measurements in a time-frequency analysis.

\subsection{Vibrations from a Fluctuating Damping Force}

The interaction between the magnetic flux from the per- manent magnets and the counteracting induced flux in the armature from the currents in the winding cables result in a damping force in the air gap [21]. The force counteracts the pulling force from the waves. Generally when more power is generated with a certain load a higher damping force affects the WEC. As a consequence the translator speed is reduced and the system is balanced.

In an ordinary 3-phase generator the phase voltages balance each other, causing an even power output. In a 1-phase generator the power output will fluctuate with the only phase present and consequently so will the damping force. In a 1-phase generator the power and damping force fluctuations inevitable cause vibrations. The damping force can fluctuate if the voltages in a 3-phase generator are not balanced. In L2 the windings were connected in an unintentional order with one phase being phase-shifted 180 degrees creating what could be called a 3-wire single phase or a quasi-one-phase generator. The unbalanced currents cause increased fluctuations in the power and damping force which can be seen in the power output fluctuations of L2.

The fluctuations in power and damping force shift with the amplitude of the currents at the same pace as the magnets pass by the windings. The base frequency for the damping force fluctuations therefore has the same frequency as the cogging, which is not so strange since the two forces depend on the same magnetic flux from the reciprocating translator magnets. The magnitude of the damping force fluctuations depends on translator speed, the electric load and how far out of the stator the translator has moved. In the May measurements the generator was connected to a rectifier bridge, a capacitive filter and resistive DC loads at $14.1 \Omega$. In the August measurements the generator was delta-connected to a purely resistive water cooled AC dump load nearby the WEC with phase resistances of $12 \Omega$. These describe two different load cases, a linear load case and a non-linear load case, as described respectively in Waters et al. [20] and Boström et al. [14].

Cogging and fluctuations in the damping force both lead to vibrations which cause an unstable translator motion. This and can potentially destroy the air gap by causing wear on the mechanical parts [35]. Vibrations may also increase wear on the sealing system in the piston rod mechanical lead-through transmission [27].

\subsection{Vibrations from Interacting Lorenz Forces}

Another frequency of vibration in the generator may come from the Lorenz force interactions between the cables inside the stator. These fluctuate with the frequency of the electric circuit, which is half the cogging frequency given in Equation (1). Thus two frequencies 
co-exist separated by a factor of 2 . The vibrations from the Lorenz forces come from inside the stator and may propagate through the WEC structure and may be seen in the sensor measurements.

\subsection{Vibrations from End Stop Impact}

End stop impact obviously happens less frequent and may produce transients with a lot higher frequencies than cogging, fluctuations in damping and Lorenz force interactions. In higher sea states end stop impact may occur in every wave period, while in smaller sea states it does not have to occur at all.

The appearance of end stop impact in the laser sensor measurements is investigated in the time domain and in the frequency domain with short time Fourier transforms (STFT) plotting the spectral content with a spectrogram.

\subsection{Spectral Analysis with FFT}

The spectral content in the laser triangulation sensor measurements are investigated in the frequency domain with Fast Fourier transform (FFT) and compared with the spectral content in simultaneous measurements with other sensors in the WEC and the measured active AC power. The purpose is to try to separate vibrations in the sensor signals from noise and to draw conclusions from comparison with the other sensors on the possible source of the vibrations in the frequency domain and if and what filtering is needed.

Frequency analysis using FFT is the most commonly used method for constant bandwidth analysis [41]. The FFT algorithm in Matlab calculates the discrete Fourier transform (DFT) described in [42]. The FFT algorithm in Matlab is used to find the spectral content in the sensor measurements within a selected measurement period.

The methods for obtaining the spectral content are well known and explained in [42]. In this paper the spectral intensity is given as log of FFT magnitude. The resulting decibel level in a power spectrum is exactly the same. The interest lies in the comparison between frequencies and relative amplitudes, not absolute amplitudes. Reference levels for the spectra are therefore not necessary. The FFT of the measured data is carried out with the parameters given in Table $\mathbf{1}$.

The frequency spacing (or resolution) in the FFT depends on the sample size $\mathrm{N}$ and the sampling period, $T_{s}$. $T_{s}$ is determined by the sampling frequency of $256 \mathrm{~Hz}$ and $N$ by the selected measuring period of $8.5 \mathrm{~s}$.

The force transducer output is not suitable for spectral analysis since it is sampling with such a low frequency. In fact it is under sampling with regard to the cogging frequency, and show a lot of aliasing, which can be spotted in the time domain comparisons.
Table 1. FFT parameters used in the spectral analysis of the measurements in May and August (excl. the force transducer).

\begin{tabular}{ccc}
\hline Parameter & Notation & Value \\
\hline Time domain & & \\
Sample interval & $T_{s}$ & $3.90625 \mu \mathrm{s}$ \\
Sample size & $N$ & 2177 \\
Sample length & $(N-1) \cdot T_{s}$ & $8.5 \mathrm{~s}$ \\
Frequency domain & & \\
Frequency spacing & $f_{s}=1 / N T_{s}$ & $0.1176 \mathrm{~Hz}$ \\
Spectrum size & $N$ components & 2177 \\
Max. frequency & $(N / 2) \cdot f_{s}=F_{\max }$ & $128 \mathrm{~Hz}$ \\
Frequency period & $F_{p}=N \cdot f_{s}$ & $256 \mathrm{~Hz}$ \\
\hline
\end{tabular}

\subsection{Time-Frequency Analysis with STFT}

Spectrograms are plotted of the laser triangulation sensor measurements to measure the frequency information over time, using the joint time-frequency functions in the Matlab STFT algorithm. The Hamming window is used in Matlab. The spectrograms are mainly presented to display the changes in spectral content and the differences between normal operation and what happens at end stop impact. The laser triangulation sensor measurements are analyzed with STFT and correlated with the instantaneous cogging frequency calculated with the speed of the translator as measured by the draw-wire sensor in the time domain.

\section{Results}

\subsection{Sea States during Measurements}

The wave height at the LRS is measured by a non-directional Datawell Waverider buoy. The buoy measures the vertical surface displacement and sends the information through radio link to the Sven Lovén Centre for Marine Studies in Fiskebäckskil. The measurement frequency is $2.56 \mathrm{~Hz}$. Spectral analysis is carried out onshore. The overall accuracy of the buoy is $3.5 \%$ of the measured value and the measuring system is presented in [11]. A significant wave height $\left(H_{S}\right)$, a mean energy period $\left(T_{E}\right)$ and a wave power density $(J)$ are calculated as halfhourly averages. In this paper, the first measurement period is taken from measurements logged on the $28^{\text {th }}$ of May with a sea state characterized by $H_{S}=1.6 \mathrm{~m}, T_{E}=$ $5.7 \mathrm{~s}$ and $J=7.2 \mathrm{~kW} / \mathrm{m}$. The second measurement period was logged on the $15^{\text {th }}$ of August with a sea state of $H_{S}=$ $1.8 \mathrm{~m}, T_{E}=6.0 \mathrm{~s}$ and $J=9.5 \mathrm{~kW} / \mathrm{m}$.

\subsection{Reference Signal and Estimation of Noise at Standstill}

The laser triangulation sensor measurements with the 
WEC at standstill separated from the buoy in October after the experiment are shown in Figure 11. The laser triangulation sensors show a rms noise level, i.e. \pm 1 standard deviation, between $0.0003-0.0008 \mathrm{~mm}$, and a peak-to-peak noise, representing 6 standard deviations of $0.002-0.004 \mathrm{~mm}$. The measured objects still seem to oscillate slightly from the waves. This is possibly due to wear on the sealing system.

\subsection{Measurements in the Time Domain}

The measurements in the time domain for $8.5 \mathrm{~s}$ from the $28^{\text {th }}$ of May between 13:00:20-13:00:28.5 are shown in Figure 12. $8.5 \mathrm{~s}$ represents a little more than a wave period to show the typical sensor amplitudes at the given sea state during a wave on the $28^{\text {th }}$ of May without the translator impacting on the upper or lower end stop. The overall signal characteristics on the scale of a wave period can thus be studied.

Close-ups of 1 second at a specific point in time between $22.5-23.5 \mathrm{~s}$ when the translator is ascending with a constant speed of approx. $0.6 \mathrm{~m} / \mathrm{s}$, are shown in Figure 13. On the smaller time scale of a second the particular relations in signal content, like frequencies and noise, can be distinguished and correlated.

Output is presented from the laser triangulation sensors, the draw-wire sensor measuring piston rod outside length, SC 5, SG 3, SG 13, the force transducer and the active AC power. The translator is in the middle position when the piston is $1185 \mathrm{~mm}$ outside the seal housing (in the water). The upper end stop compression spring does not contact the translator until the piston has moved 2092 $\mathrm{mm}$ outside the seal housing and into the water. The lower end stop compression spring contacts the translator when the piston rod outside length is $295 \mathrm{~mm}$. These impacts are not happening during the wave period in Figures 12 and 13. Figure 14 displays the sensor measurements for an equally long time period of $8.5 \mathrm{~s}$ on the $15^{\text {th }}$ of August. The Strain gauges did not function at this moment in time and cannot be displayed for this time period. The elevated noise levels in PRLS 1 - 3 and the draw-wire sensor has already been explained in [30]. A faulty ground in the underwater substation may be the reason. It was corrected after the underwater substation was picked up in June, fixed and re-launched a week later.

The close-ups of 1 second in Figure $\mathbf{1 5}$ are taken from Figure 14 between 20.7 - 21.7 s. It is important to point out that the two measurement periods are taken with the WEC connected to two different load cases described in Section 4.3. This is the reason for the different generated power visible in the active AC power output plots from the WEC. However, the axial force in the buoy line is
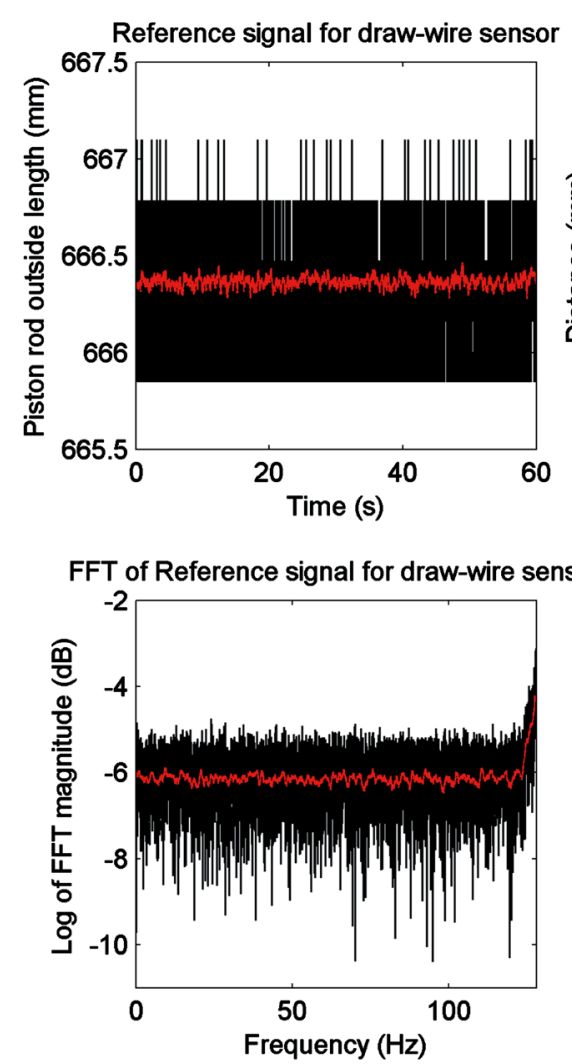
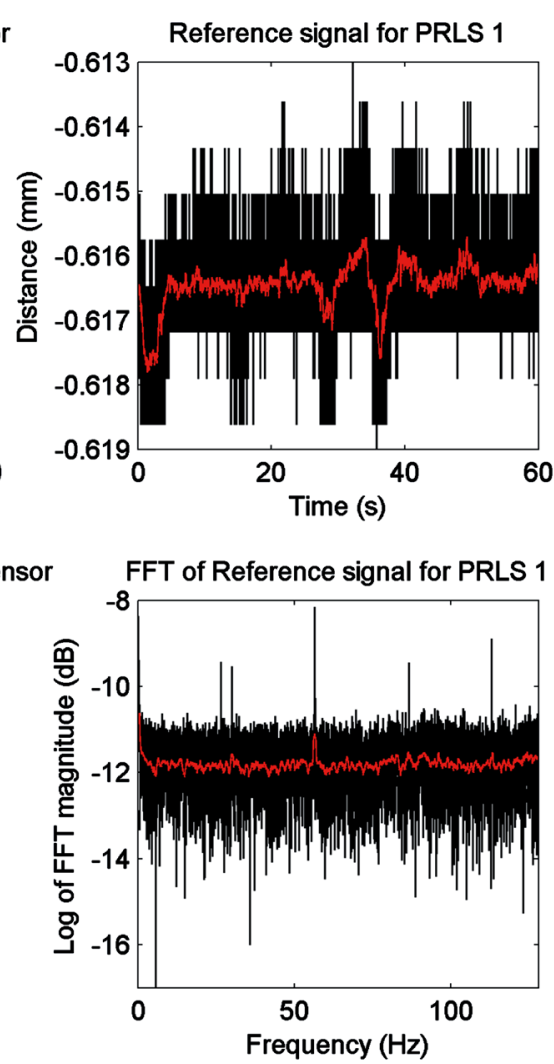
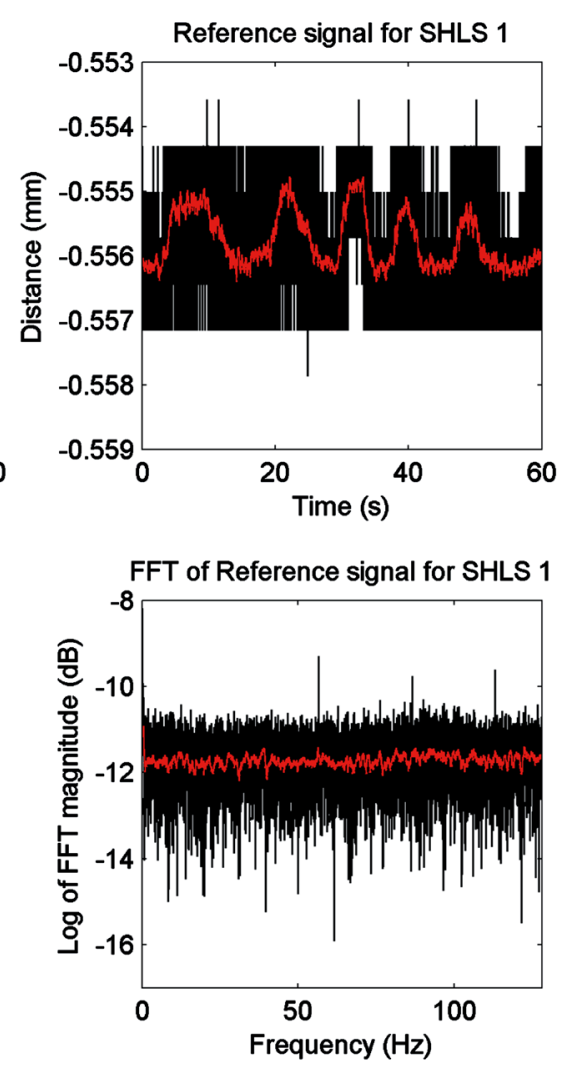

Figure 11. Output and spectrum with FFT for the draw-wire sensor, PRLS 1 and SHLS 1 at generator stand still in October. 

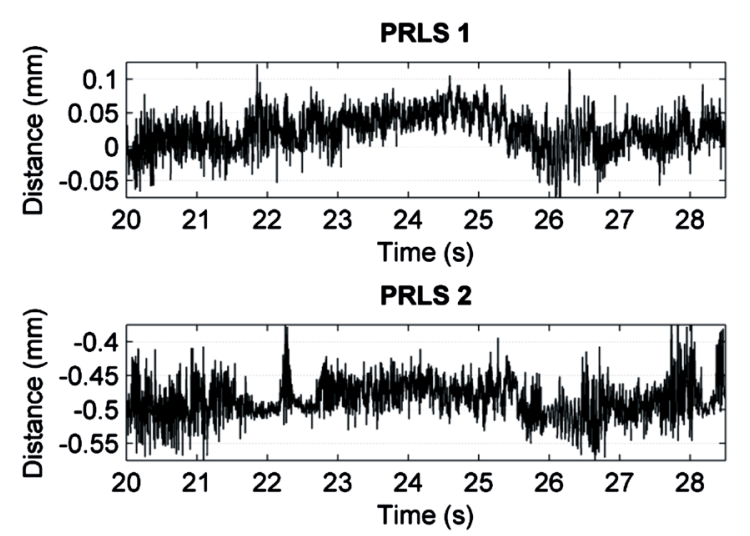

PRLS 3
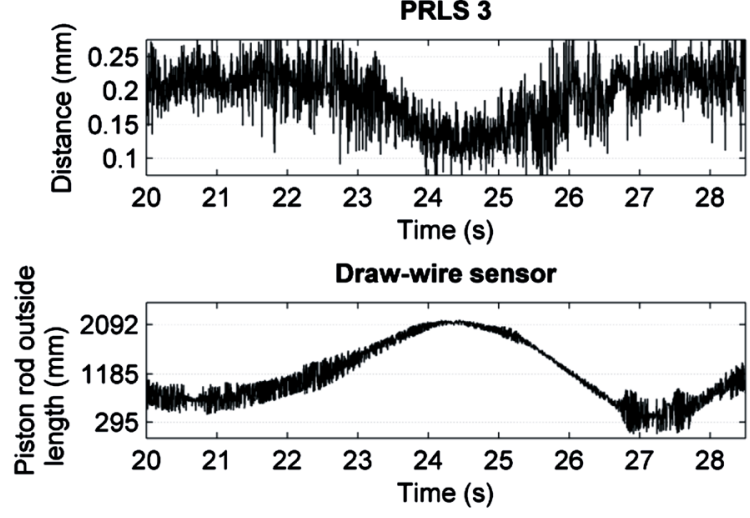

Force transducer

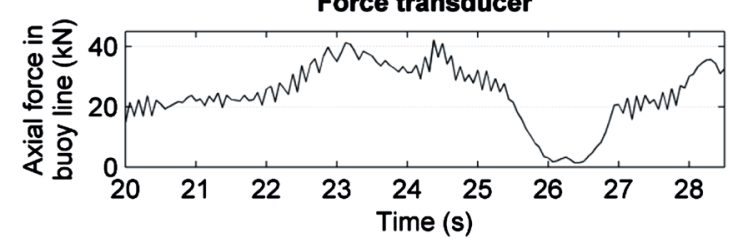

Active AC-power from WEC
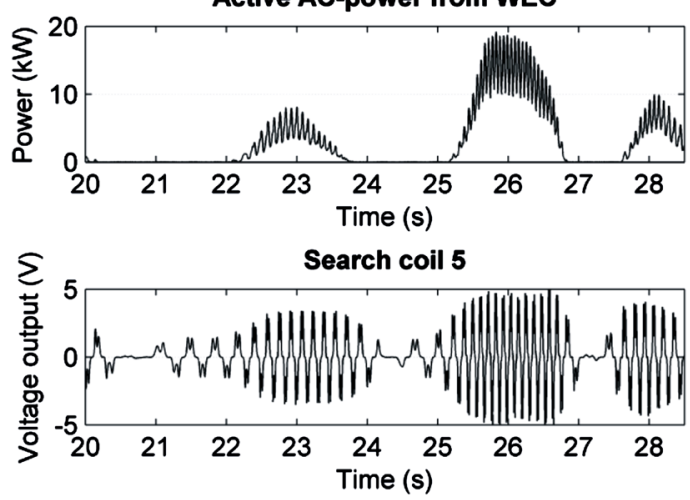

SHLS 1

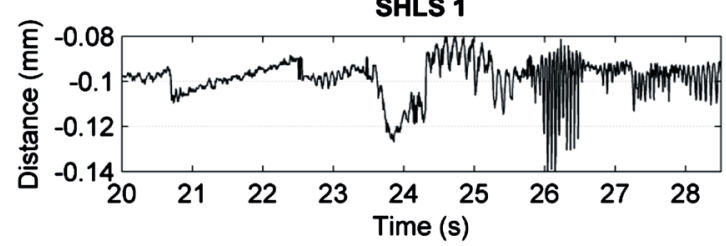

SHLS 2

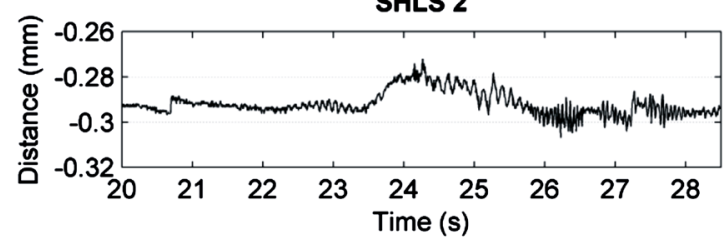

SHLS 3

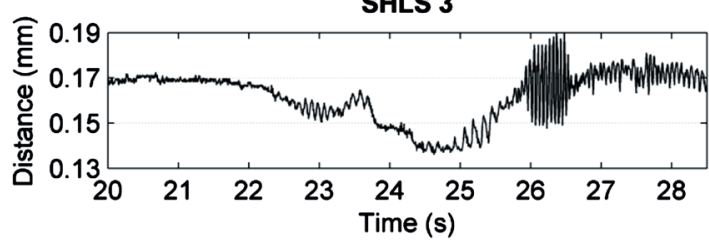

SHLS 4

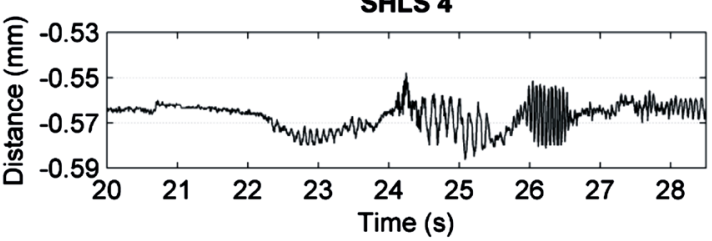

Strain gauge 3

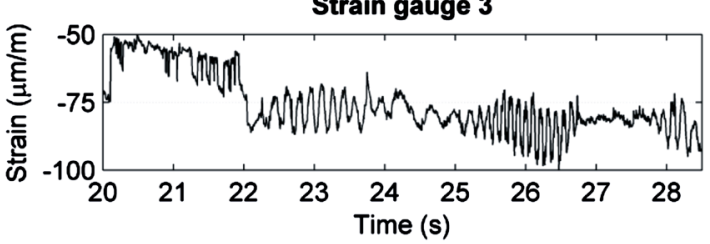

Strain gauge 13

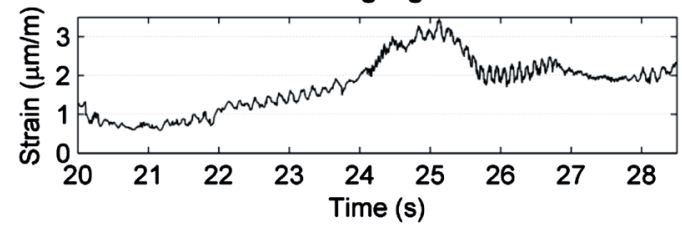

Figure 12. Measurements from one wave period in the WEC in May 28, 13:00:20-13:00:28.5 from PRLS 1 - 3, SHLS 1 - 4, the draw wire sensor, the force transducer, SG3, active AC power, SC5, and SG13.

comparable in magnitude and fluctuates similarly in both cases. The average translator speed in Figure $\mathbf{1 3}$ is 0.6 $\mathrm{m} / \mathrm{s}$, while it is $0.7 \mathrm{~m} / \mathrm{s}$ in Figure 15. The higher translator speed consequently results in a higher average frequency of $14 \mathrm{~Hz}$ for the cogging and fluctuations in damping force as presented in Figure 15, compared to 12 $\mathrm{Hz}$ in Figure 13. The electric frequency of the currents in both the May and the August measurements oscillate with half the cogging frequency, which can be seen in the output of the SC 5.

The search coils measure the passage of each permanent magnet in the air gap. The magnetic field from the strong magnets completely dominate the visible output in the time domain. The force transducer is visibly under 

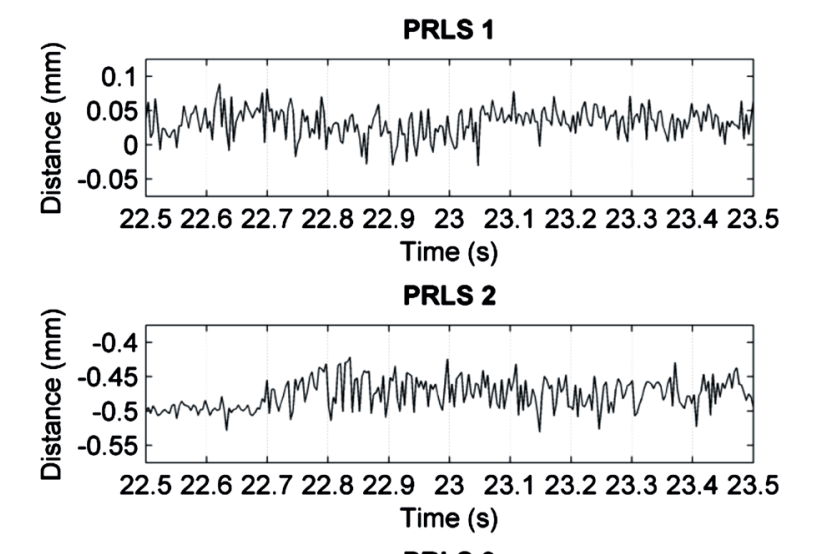

PRLS 3
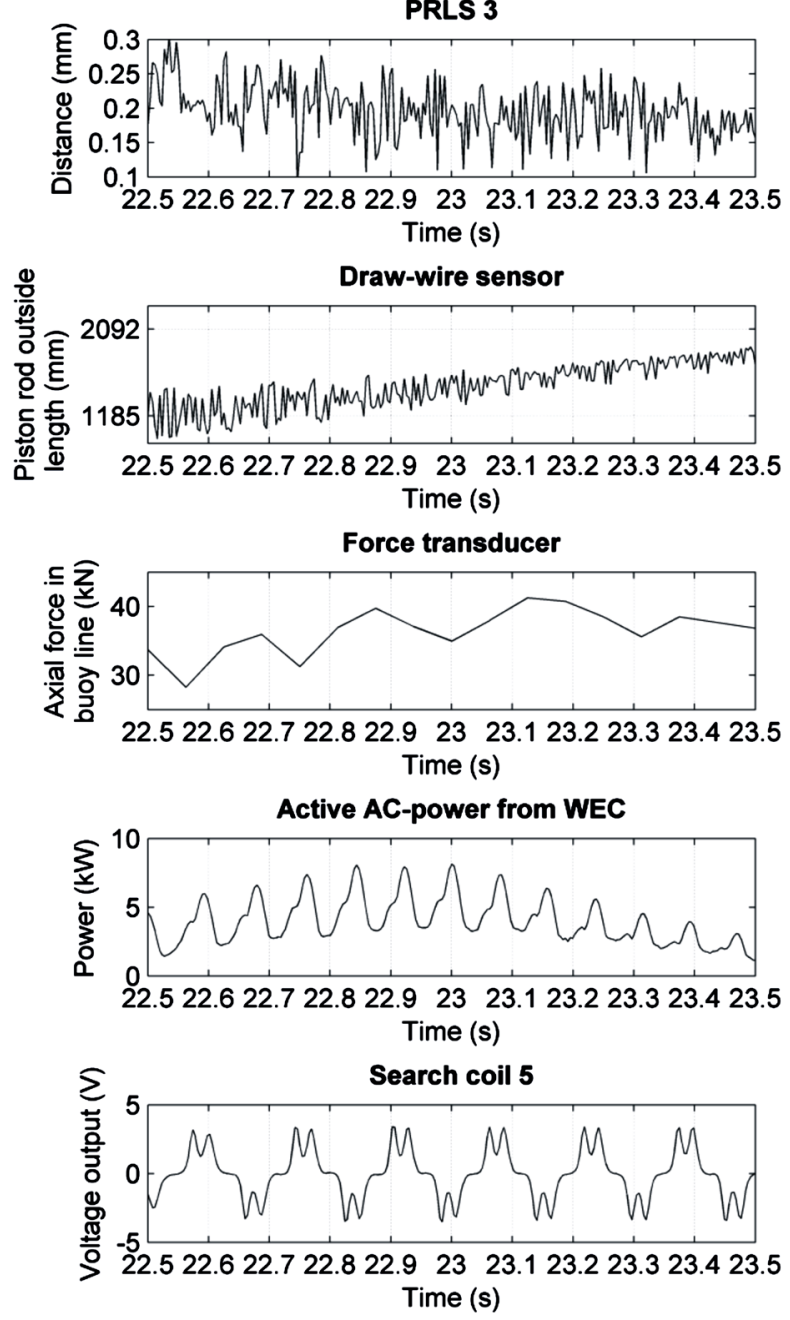

Figure 13. Measurements from $1 \mathrm{~s}$ in May 28, 13:00:22.5-13:00:23.5 from PRLS 1 - 3. SHLS 1 - 4, the draw wire sensor, the force transducer, SG 3, active AC power, SC 5, and SG 13.

sampling and show aliases at $4 \mathrm{~Hz}$ in the May and $6 \mathrm{~Hz}$ in the August measurements. The PRLS $1-3$ have a visibly lower noise level in August.

\subsection{Measurements in the Frequency Domain}

FFT calculations are performed in Matlab on the data
SHLS 1
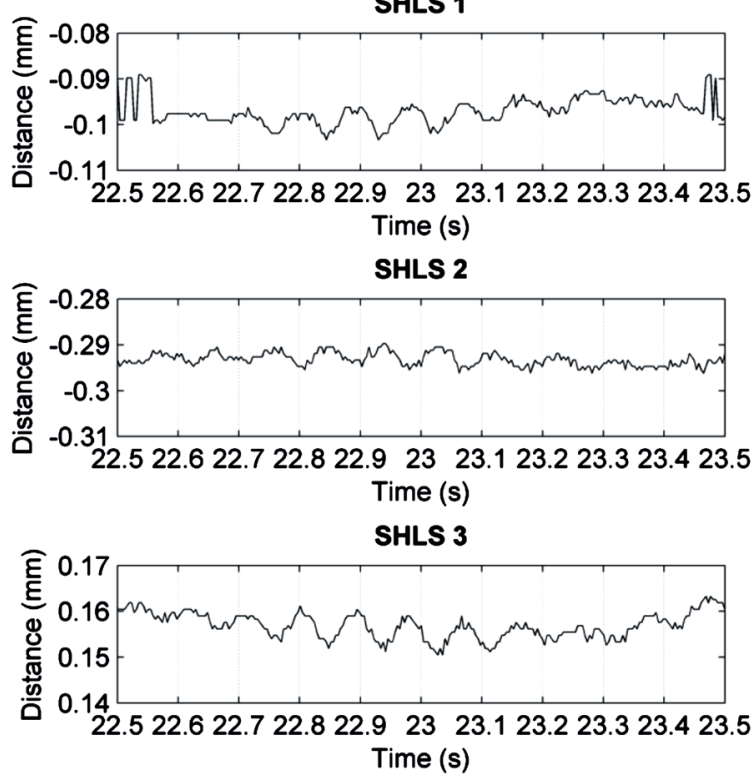

SHLS 4

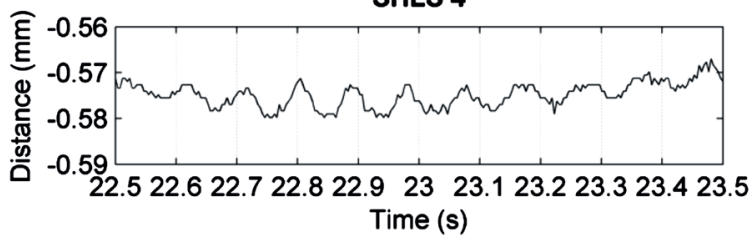

Strain gauge 3

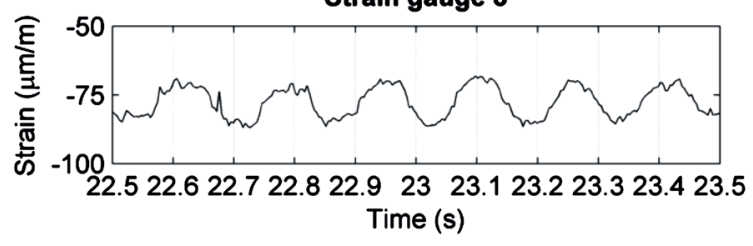

Strain gauge 13

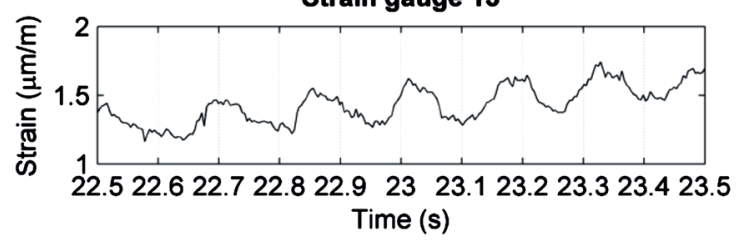

from both $8.5 \mathrm{~s}$ measurements in May and August to enable spectral analysis. Log of FFT magnitude in $\mathrm{dB}$ is presented in order to display the relative intensities of the different frequencies adding information to the time domain studied above. The results are presented in two graphs with selected offset decibel values added to each 
PRLS 1

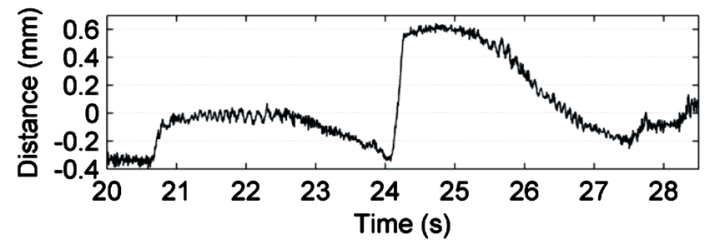

PRLS 2

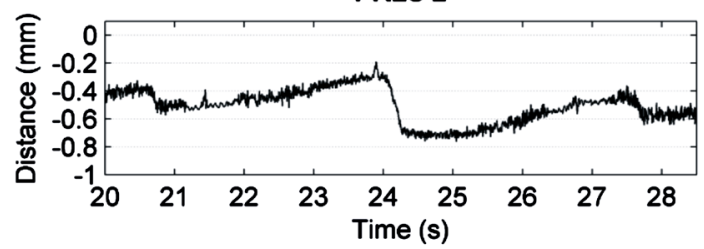

PRLS 3
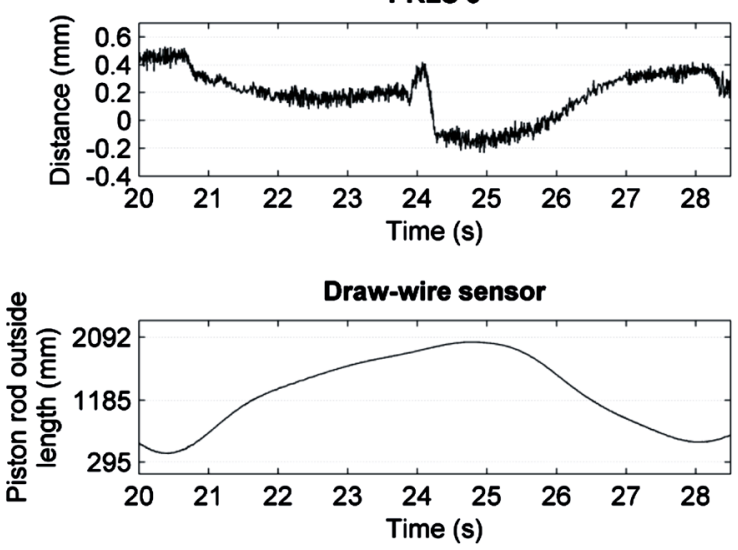

Force transducer
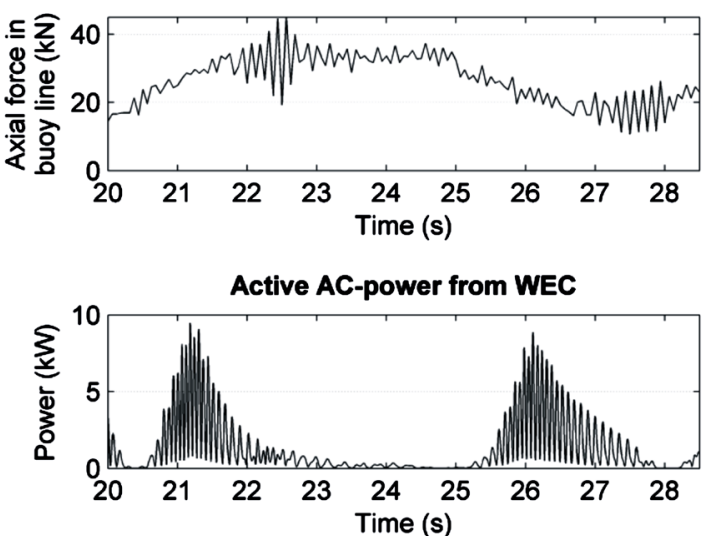

SHLS 1

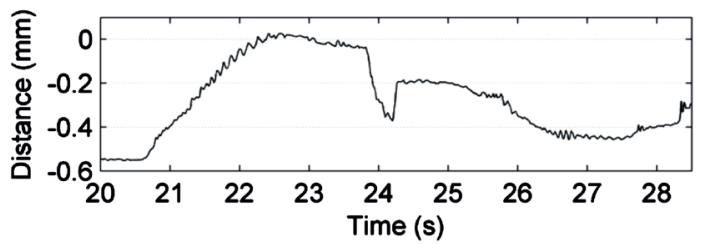

SHLS 2

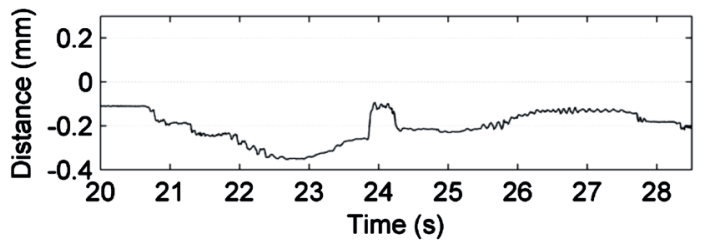

SHLS 3

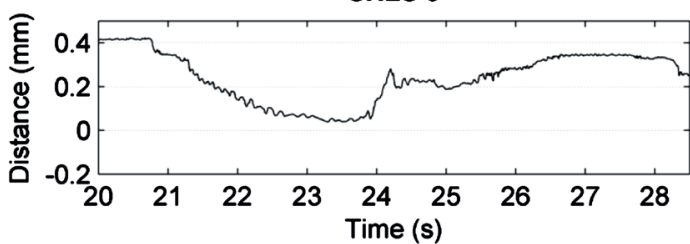

SHLS 4

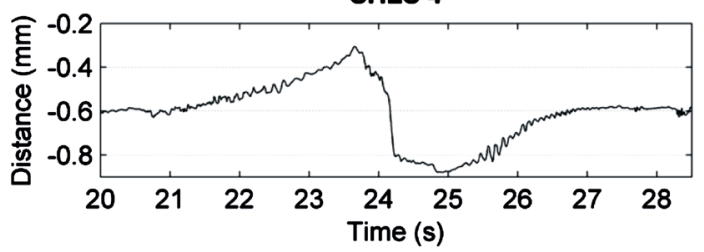

Search coil 5

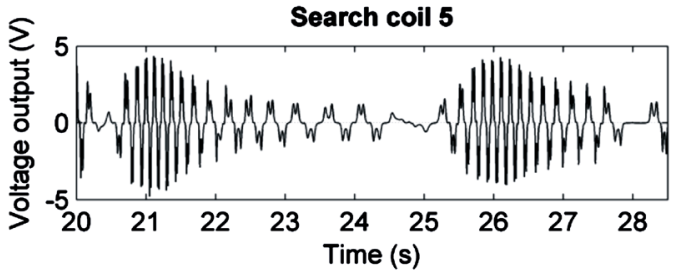

Figure 14. Measurements from one wave period in August 15, 00:00:20-00:00:28.5 from PRLS 1 - 3, SHLS 1 - 4, the draw wire sensor, SC 5, active AC power, and the force transducer.

curve for the purpose of not concealing each other. Centred moving averages with a sliding window of 9 frequency spacings are superimposed on the spectra to clarify the peaks. The spectra for the May measurements are displayed in Figure 16 and for the August measurements in Figure 17. The Nyquist frequency is $128 \mathrm{~Hz}$ for both cases. The data and the original units of measurement for the different curves are found in Figures 12 and 14.

\subsection{Measurements in the Time-Frequency Domain}

Figure 18 presents time-frequency analysis on PRLS 3 and SHLS 3 for the measurements on the $28^{\text {th }}$ of May between 13:16:00-13:17:00 hours, incl. end stop impact. Figure 19 presents the same analysis performed on data 
PRLS 1

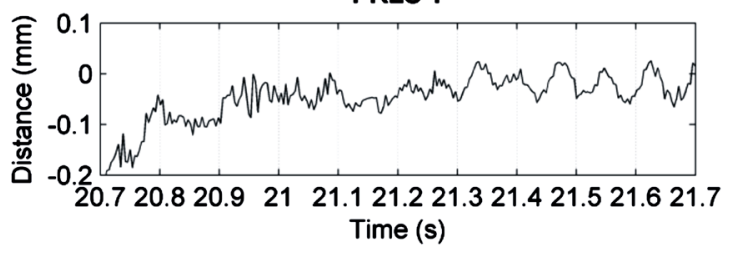

PRLS 2

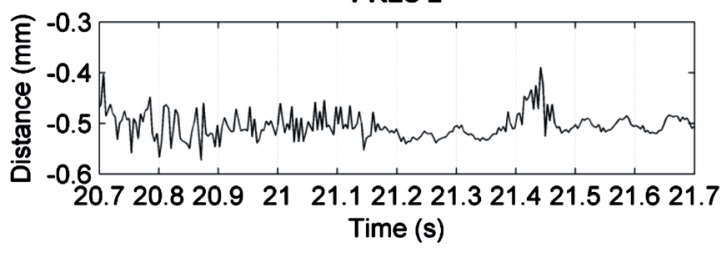

PRLS 3
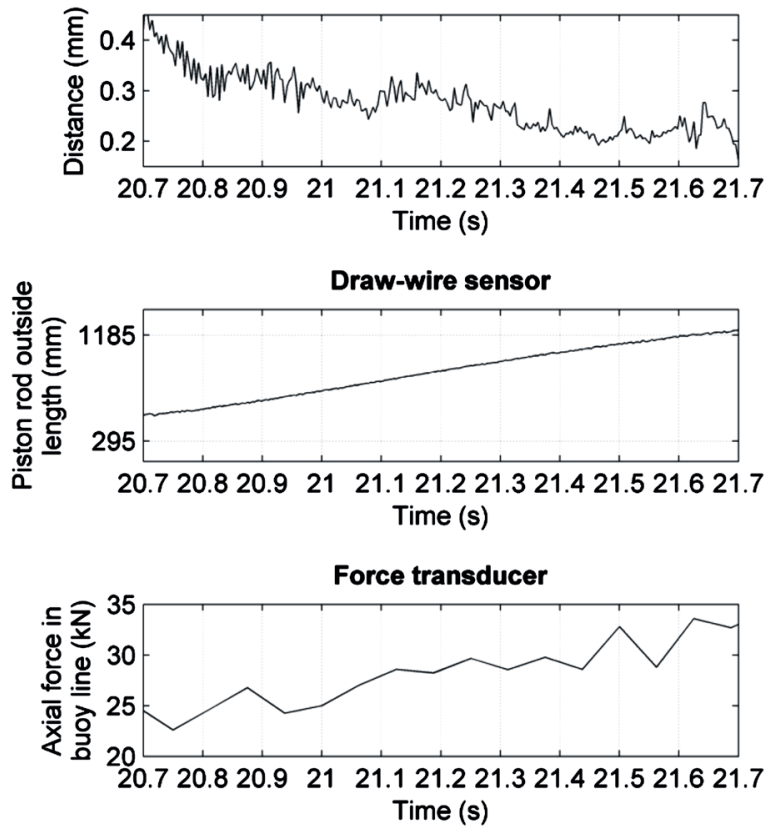

Active AC-power from WEC

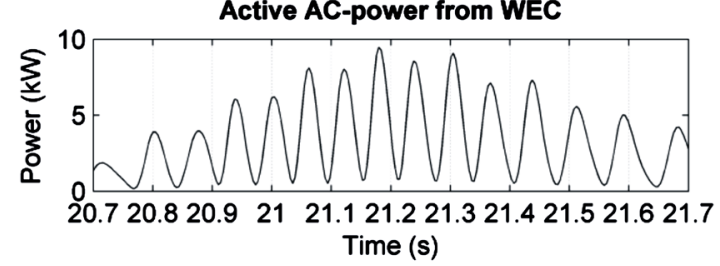

SHLS 1

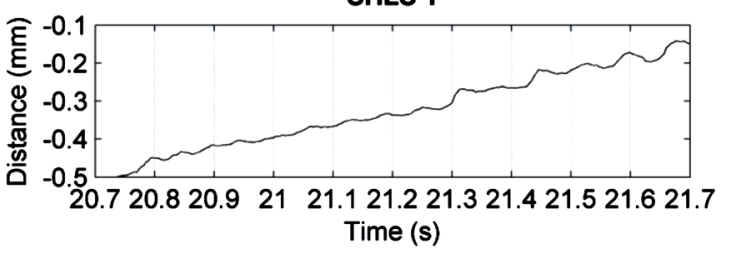

SHLS 2

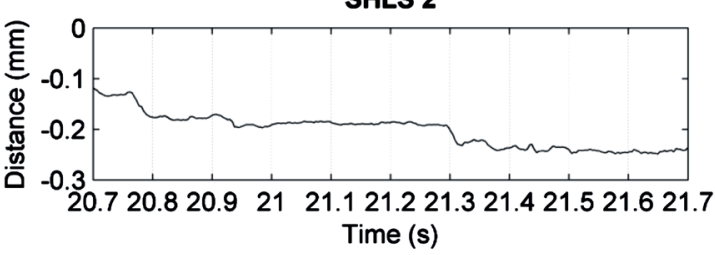

SHLS 3

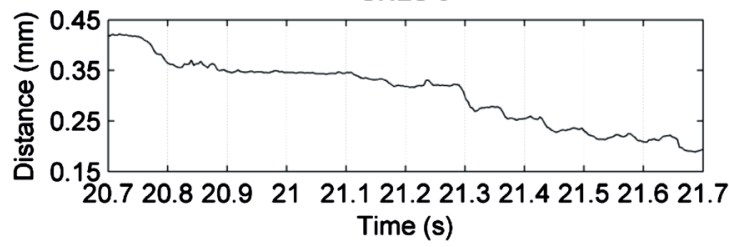

SHLS 4
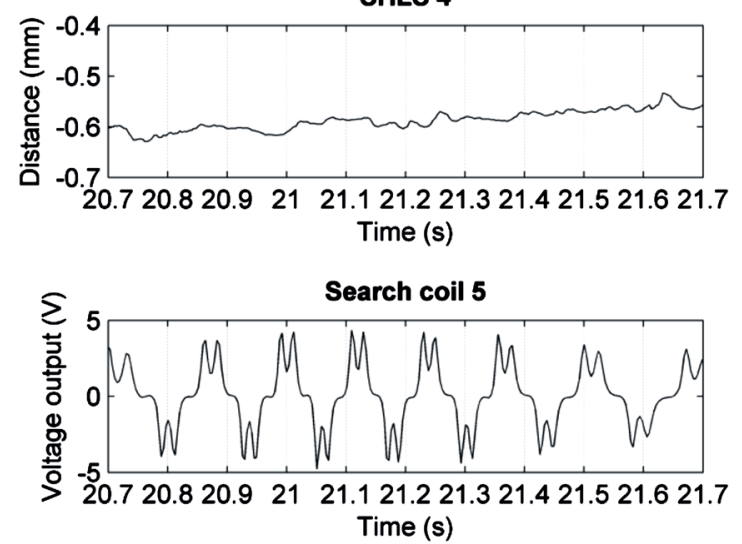

Figure 15. Measurements from $1 \mathrm{~s}$ in August 15, 00:00:20.7-00:00:21.7 from PRLS 1 - 3, SHLS 1 - 4, the draw wire sensor, SC 5 , active AC power, and the force transducer.

from the $15^{\text {th }}$ of August between 00:00:00-00:01:00 hours for PRLS 1 and SHLS 1, with two end stop impacts. The sensor output and spectral content in Figures 12-17 show that PRLS 1 - 3 and SHLS 1 - 4, respectively, contain more or less the same signal and noise characteristics. In the continued time-frequency analysis with STFT only one sensor from each group needs to be used for calculating the representative power spectral density for the sensor groups. The selected sensors measure in the directions of the incoming waves at the particular times in question and will therefore be the sensors with the largest output within each group of sensors.

The sensor output is first presented in the time domain over one minute of sampling for both May and August. A centred moving average (CMA) with a window of 51 samples is applied to the May measurement with PRLS 3; see superimposed red line in Figure 18. Two graphs showing the power spectral density is then plotted 


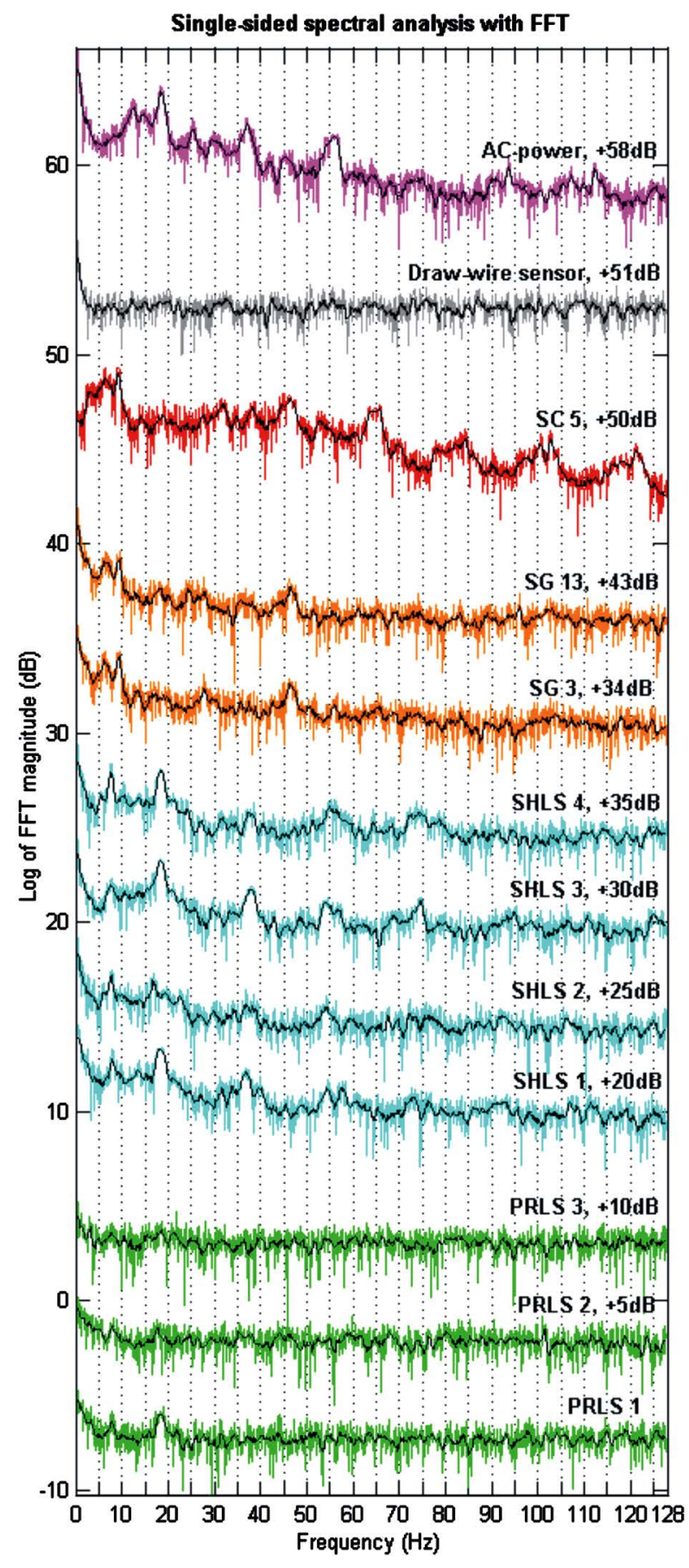

Figure 16. Magnitude spectra for PRLS 1 - 3. SHLS 1 - 4, SG 3, SG 13, SC 5, the draw-wire sensor, and measured active $\mathrm{AC}$ power for a measurement period of $8.5 \mathrm{~s}$ on May the 28th between 13:00:20-13:00:28.5 hours.

underneath. The first covers up to the Nyquist frequency of $128 \mathrm{~Hz}$. Below that a close-up displays the power spectral densities within the cogging bandwidth in greater detail. The same is performed for SHLS 3 in May and SHLS 1 in August and presented PRLS 3 and 1 in Figures 18 and 19 respectively.

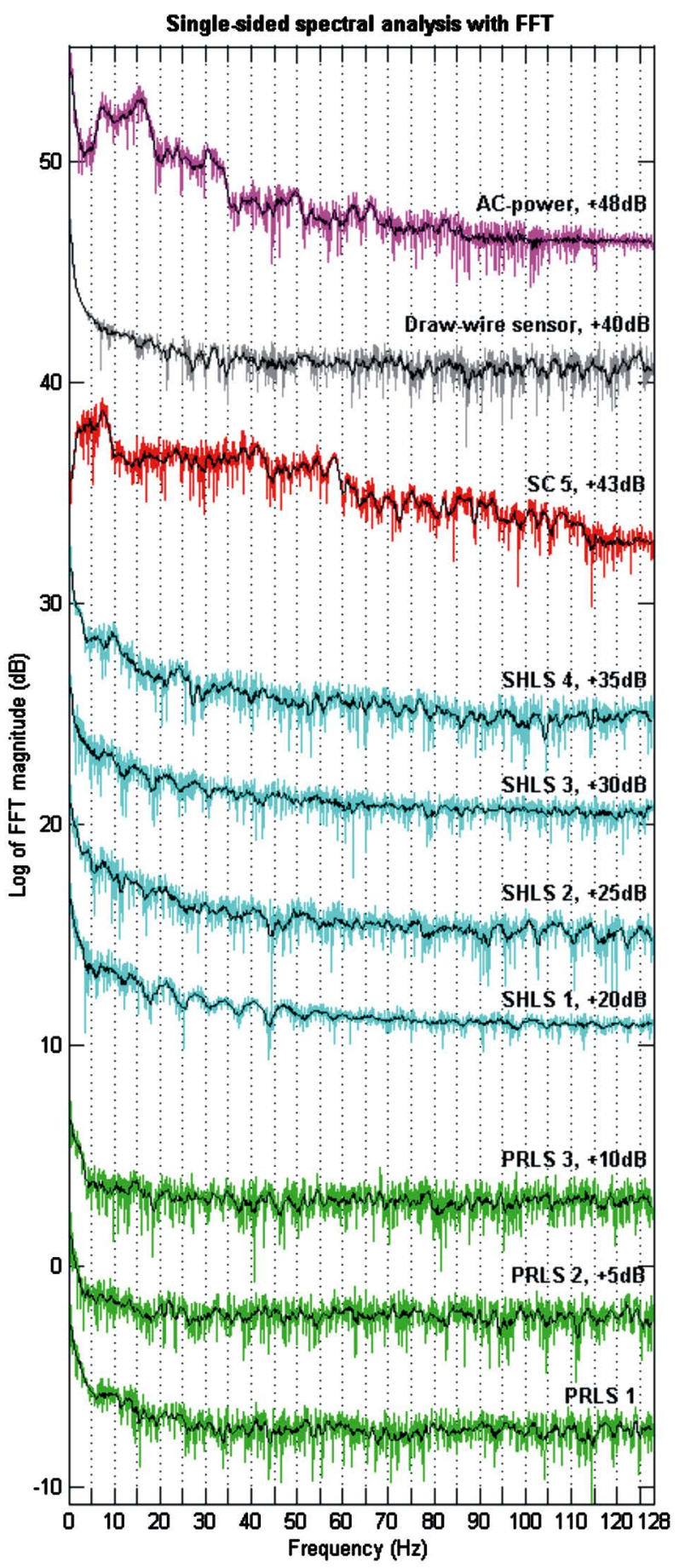

Figure 17. Magnitude spectra for PRLS 1 - 3, SHLS 1 - 4, SC 5, the draw-wire sensor and measured active AC power for a measurement period of $8.5 \mathrm{~s}$ on August the 15th between 00:00:20-00:00:28.5 hours.

STFT in Matlab is used with a Hamming window with NFFT length of 145 for the PRLSs and 250 for the SHLSs. NFFT is a value for setting the spectral resolution. A higher value has a smoothing effect on the output due to increased window overlaps. 

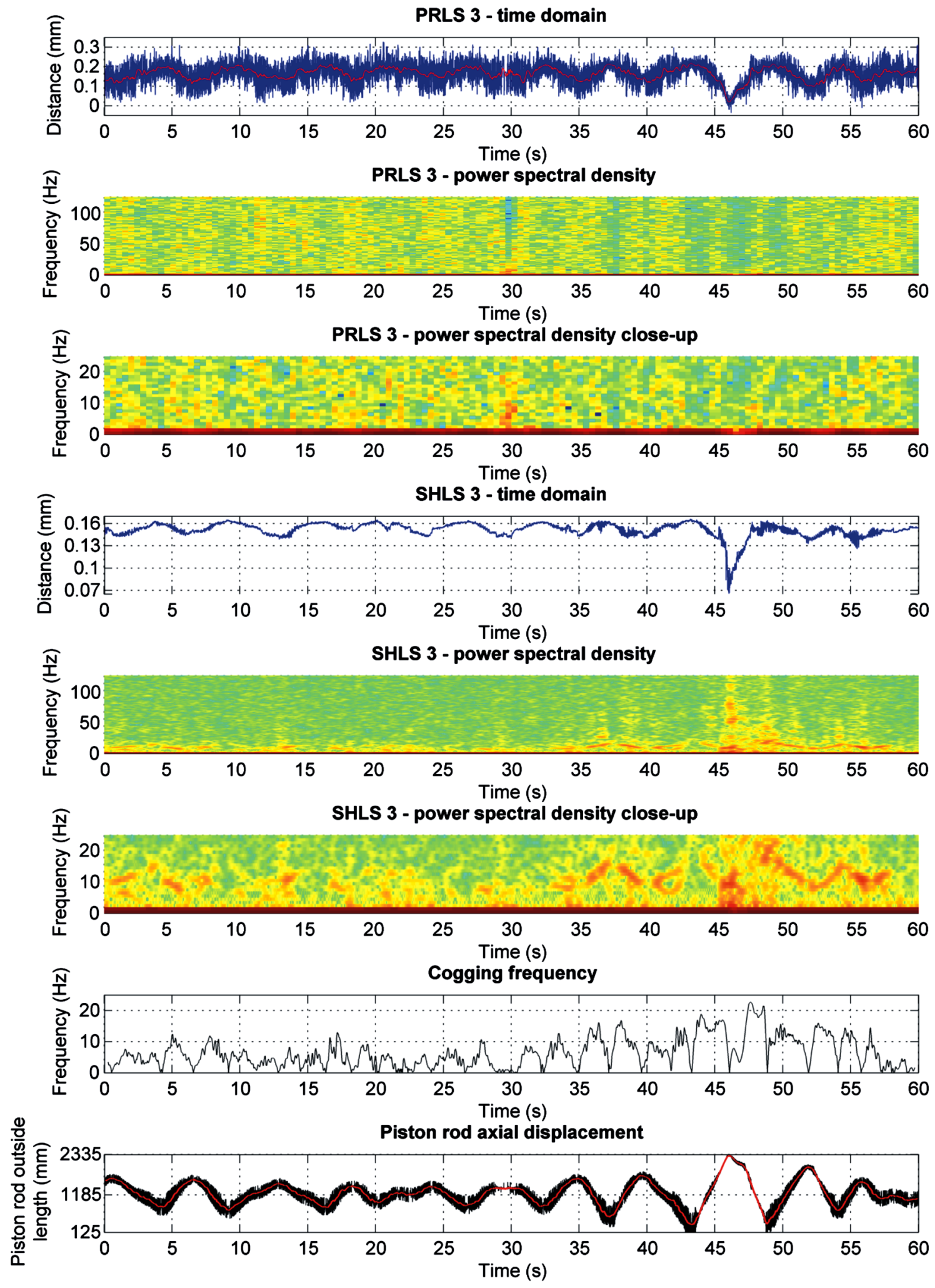

Figure 18. Measurements on May 28th between 13:16:00-13:17:00 hours. PRLS 3 for $60 \mathrm{~s}$ in the time domain. Power spectral densities for PRLS 3 up to the Nyquist frequency followed by a close-up of the cogging bandwidth. SHLS 3 for $60 \mathrm{~s}$ in the time domain followed by power spectral densities for SHLS 3 up to Nyquist frequency and a close-up of the cogging bandwidth. The instantaneous cogging frequency and piston rod outside length measured by the draw-wire sensor. End stop impact occurs after $46 \mathrm{~s}$. 

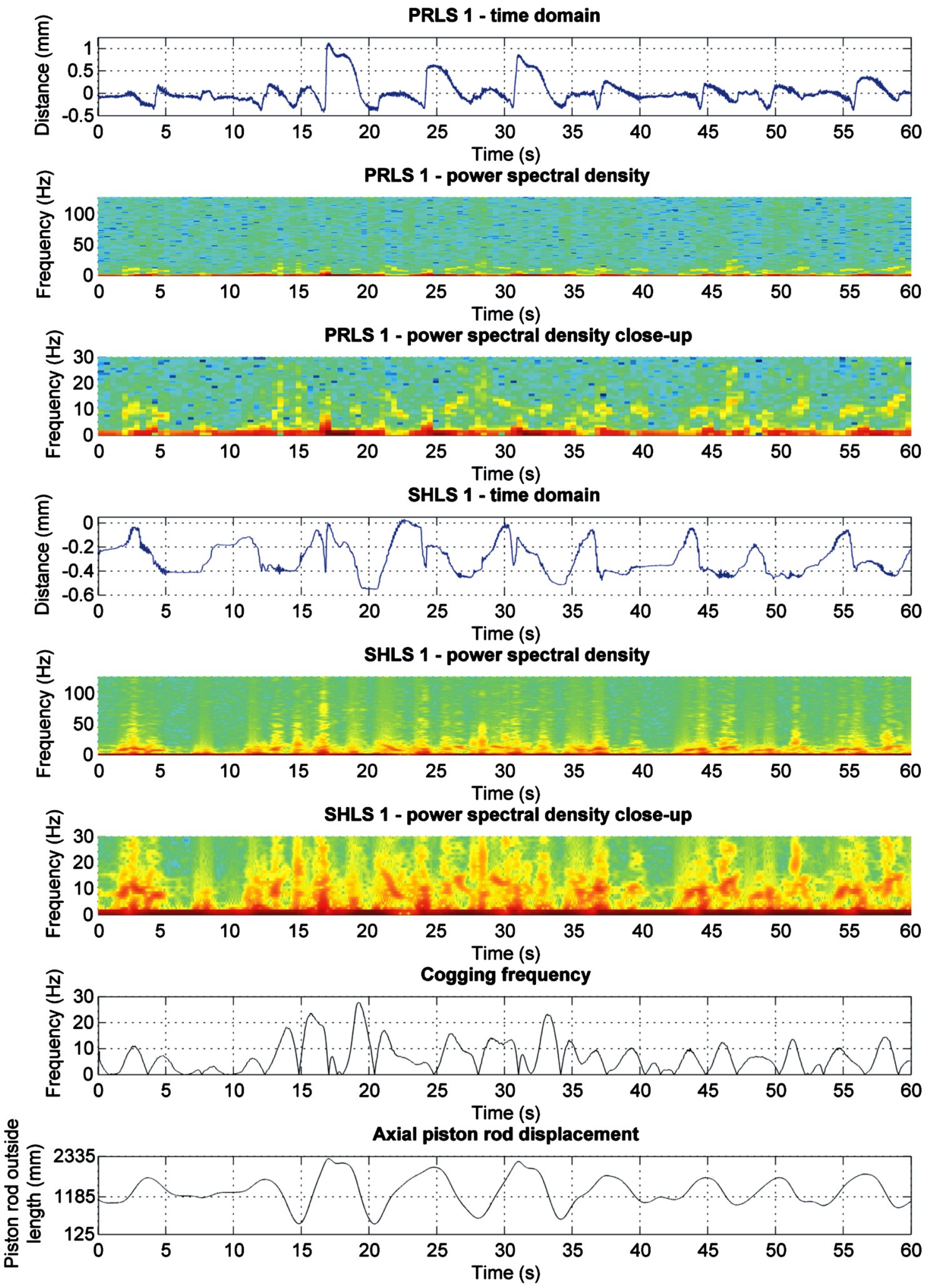

Figure 19. Measurements on August 15th between 00:00:00-00:00:01 hours. PRLS 1 for 60 s in the time domain. Power spectral densities for PRLS 1 up to the Nyquist frequency followed by a close-up of the cogging bandwidth. SHLS 1 for $60 \mathrm{~s}$ in the time domain followed by power spectral densities up to the Nyquist frequency and a close-up of the cogging bandwidth. The instantaneous cogging frequency and piston rod outside length measured by the draw-wire sensor. End stop impact occurs after $17 \mathrm{~s}$ and $31 \mathrm{~s}$. 
Piston rod axial displacement, which with and offset correlates to translator position, is presented at the bottom of Figures 18 and 19. In this section the position is foremost used to display the end stop impacts, but also to give information about the position of the transmission and translator during operation. When the piston rod outside length is $1185 \mathrm{~mm}$ the translator is in its vertical middle position with the centre in the middle of the stator. When the translator hits the upper end stop the piston rod outside length is $2335 \mathrm{~mm}$. The lower end stop is impacted on when the piston rod has a $125 \mathrm{~mm}$ outside length. The sampled measurements include one upper end stop impact in May at $46 \mathrm{~s}$ and two end stop impacts in August at $17 \mathrm{~s}$ and $31 \mathrm{~s}$.

The power spectral densities for the different frequencies may be compared with the instantaneous cogging frequencies, based on the translator speed and the magnetic pole width; see Equation (1) in Section 4.2. The translator speed is calculated by Newton's difference quotient to find the derivatives of the axial piston rod displacement. A least squares method with a linear fit and a window of 51 samples sweeping the measurements of the piston rod outside length is applied. In May the piston rod outside length is represented by a CMA calculated with a sweeping window of 101 samples, due the increased noise level.

The next step is to calculate the instantaneous cogging frequency by dividing the translator speed with the magnetic pole width of $50 \mathrm{~mm}$ and turning the amplitudes into magnitude by using the absolute value. The resulting instantaneous cogging frequency is displayed in the second graph from the bottom in both Figures 18 and 19. The peaks in cogging frequency do not seem to be affected by the selected windows sizes, just the overall smoothness is visibly affected.

\subsection{Close Up of End Stop Impact in the Time Domain}

In order to suggest a suitable filter for further studies with calculations of the macro displacements in the mechanical lead-through transmission a comparison between 5 filters is presented in Figure 20. The inverse FFT is a mathematical filter with an ideal response function separating all frequencies above the cut-off frequency, which is useful to investigate what signal may contain in the time domain with a limited number of accepted frequencies. In post-measurement signal processing it is possible to use the ideal inverse FFT (IFFT) low-pass filter with a chosen cut-off frequency. The CMA filters with a window of 51 samples have been proposed and motivated in [30].

The results in Figure 20 show that continued use of the CMA filter is adequate for evaluating the larger motions without excluding too much information or cutting

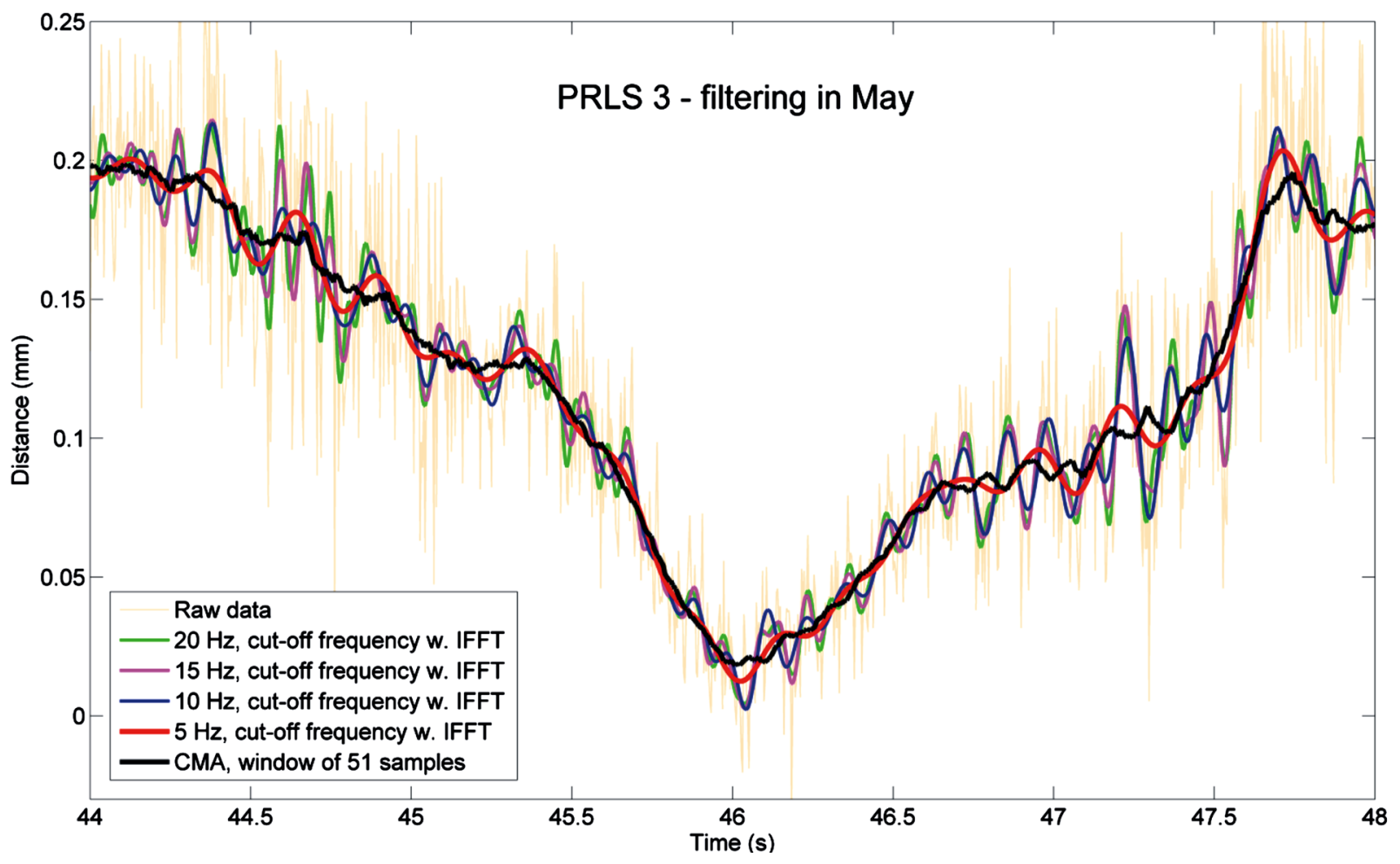

Figure 20. Close-up of output from PRLS 3 at end stop impact with different IFFT filters and a CMA filter applied on the May measurements. 
of peaks too much, even though vibrations should be further investigated by other means and treated separately if those were in focus for the study. Figure 21 indicates that a smaller CMA window of 21 samples would follow the steepest gradients more precisely. However, with more noise it is not necessarily better for the investigation. The smoothing aspect is important in order to give a meaningful content to the measurements when they are combined to calculate the tilt angles and azimuth angles of the measured objects. The results from Figures 18 and 19 suggest that an ideal low-pass filter would not be able to include all vibrations and separate the noise at the same time for a more meaningful study of the relative displacements since the vibrations are spread out over such a wide band at end stop impact. However, the CMA filter responds well to the shifting magnitudes. It is thus concluded that a CMA filter suits the data from the laser triangulation sensors for further investigations into the results with regard to performance of the mechanical device.

\section{Discussion}

The aim of the paper is to investigate the signal and spectral content in the time and frequency domain, to investigate vibrations and noise, and to find a suitable filter for further refinement of the signal to separate noise from actual physical displacement.

Normally the currents, voltages and flux waves in a 3-phase generator balance each other and superimpose to create a smooth resulting armature flux with a smooth damping force. However, in WEC L2 one of the phases were unintentionally phase shifted 180 degrees creating a combined unbalanced quasi 1-phase voltage. The result

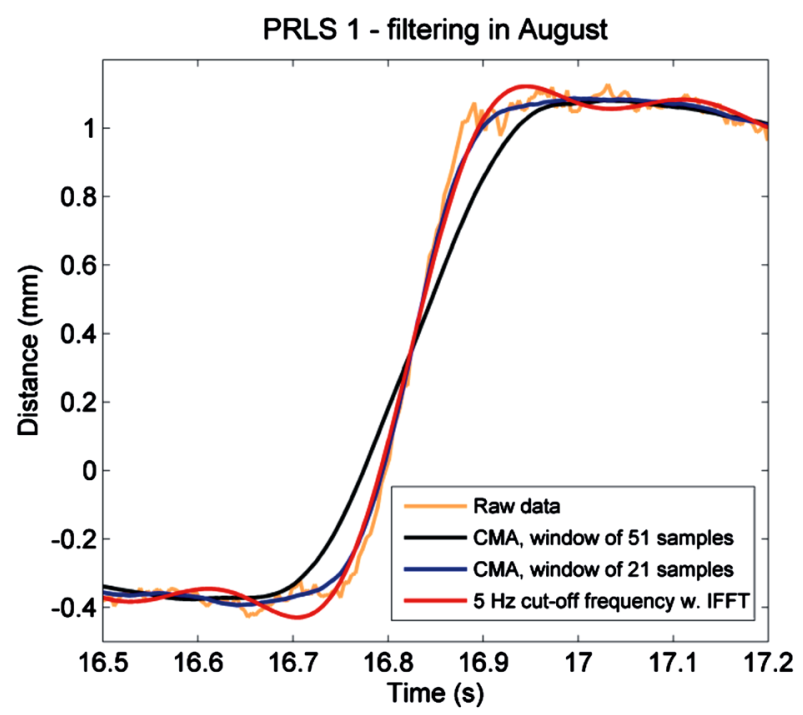

Figure 21. Close up of two CMA filters with different window size at end stop impact in the August measurement. was a generator with increased fluctuating damping force at the same frequency as the cogging, resembling that of a 1-phase generator.

If we have the generator connected to a purely deltaconnected resistive load the cogging is more pronounced, than if it is connected to a non-linear load case with a rectifier, capacitive filter and a DC load, as described in [14]. The damping force is affected by the smoothing from the capacitive filter. The capacitors discharge maintaining the power for short time intervals when the WEC is connected to the DC load like a pressure accumulator in a hydraulic system. It evens out the fluctuations in the damping load as the WEC is disconnected from the load by the rectifiers at lower production levels.

Theoretically the cogging bandwidth starts at very low frequencies from translator standstill and increase up to approximately $20 \mathrm{~Hz}$. However, the cogging is most pronounced between 5 and $20 \mathrm{~Hz}$. which has to do with the translator quickly picking up speed and maintaining it rather constant throughout each half cycle between the turning points. The reason for this has to do with the non-linear loading case. The electrical frequency of the generator is directly proportional to the speed of the translator. Maximum power is achieved during minimum and maximum line force assumed with generator stroke length. When the translator changes its direction it changes the phase order of the 3-phase voltage. With the generator connected to a non-linear load case the controlling DC-level, after the diode rectifiers, limits the translator speed to some extent and makes it more constant. If the translator speed is low, inducing a no-load voltage below the DC-voltage level, no power is extracted and the speed of the translator is allowed to increase without damping. This explains the form of the power curves in May and the reason for the appearance of the cogging plateau.

The amplitude of the fluctuating damping force depends on the number of poles activated inside the stator, which in turn depends on how far out of the stator the translator has moved. The cogging force at the longitudinal outlet ends of the stator will mainly be affected if the translator leaves one of the outlet ends of the stator. The speed of the translator varies and the number of poles inside the stator decrease towards the end stops. Both frequency and amplitude of the vibrations from cogging and fluctuating damping force decrease towards the end stops. This can be seen in the time domain in Figures 12 and $\mathbf{1 4}$ and is also visible in the spectrograms of Figures 18 and 19.

Increased induction occurs at elevated translator speed. At $26 \mathrm{~s}$, in the May measurements of Figure 12, the translator drops down as the axial buoy line force reaches almost $0 \mathrm{kN}$. Overall increased mechanical vibrations can be seen in the measurements from PRLS 1 - 3, SHLS 
1 - 4, SG 3 and SG 13 at this point in time. At a constant translator speed of $0.6 \mathrm{~m} / \mathrm{s}$ the damping fluctuations and cogging coexist at $12 \mathrm{~Hz}$; see Figure 13. The same frequency can also be seen in the active $\mathrm{AC}$ power.

The overall cogging bandwidth can be seen in the active AC power in Figure 16. It can be compared with the peaks in the laser triangulation sensor output. The cogging frequencies are apparent there, specifically at $18 \mathrm{~Hz}$ corresponding with the largest peak in the power curve. $18 \mathrm{~Hz}$ corresponds to a translator speed of $0.9 \mathrm{~m} / \mathrm{s}$.

Cogging occurs over a bandwidth, during measurements for more than a second, and in the spectral analysis. The peak at $18 \mathrm{~Hz}$ and the multiple harmonics thereof are clearly seen in the laser triangulation sensor measurements. In the time domain, in Figures 13 and 15, the cogging frequency can be seen in the laser triangulartion sensor measurements at 12 and $14 \mathrm{~Hz}$, respectively, for the two cases presented. These values correspond to a translator speed of 0.6 and $0.7 \mathrm{~m} / \mathrm{s}$ and correlate well with the oscillations in the active $\mathrm{AC}$ power with the peaks between $5-20 \mathrm{~Hz}$ in Figures 16 and 17. In Figure 17 for the August measurements the frequencies are there but not at all as apparent as in May. However the fluctuations can be seen in Figure 15.

The results in Figure 13 show that SG 3 and SG 13 oscillate at half the cogging frequency, i.e. $6 \mathrm{~Hz}$ at a constant translator speed of $0.6 \mathrm{~m} / \mathrm{s}$. This is the frequency of the electrical circuits and the magnetic circuit at this particular translator speed. It can be concluded that the source is the Lorenz forces between the cables in the stator. Peaks are seen in Figure $\mathbf{1 6}$ at the bandwidth of the SC 5 measurements. SC 5 keeps absolute track of the magnets passing by the sensor. The signal oscillates at 6 $\mathrm{Hz}$. The cogging frequency, which is twice the frequency of the Lorenz forces can thereby be verified at this speed. The Lorenz forces spread to all sensors, but the cogging do not seem to reach the inner frame work or the capsule.

The Lorenz forces in the stator are possible to detect with SG 3 and SG 13. The vibrations propagate through the inner framework and over to the capsule. The inner framework is almost completely separated from the capsule apart from four horizontal and rectangular plates nearby the upper end stop. These plates are mainly intended for internal support when the WEC is lying down during transportation. They do not carry any mechanical load during operation apart from when bending of the capsule and superstructure might subject them to buckling as large waves pull the buoy line hard towards the guiding funnel. Nevertheless, vibrations are apparently transmitted through them from the stator through the inner framework to the capsule.

The oscillations in the PRLS 1 - 3 measurements in May indicate that the vibrations in the moving translator from cogging and fluctuating damping force propagate through the piston rod and into the seal housing via the sealing components. The vibrations may be transmitted through the double hinged link and up through the piston rod, but the rubber gasket suspending the seal housing isolates the top plate from the vibrations, since the capsule strain gauge do not pick up the cogging frequency. The Lorenz forces in the stator also seem to reach the laser triangulation sensor measurements somewhat.

The vibrations from cogging and fluctuation in the damping force seem to be generally higher in August. The cogging was most pronounced within the bandwidth of 5 to $20 \mathrm{~Hz}$. This can be seen in the spectrograms comparing Figures 18 and 19. The frequencies with high relative spectral density seem to coincide rather well with the cogging frequencies. The laser triangulation sensor output in the time domain show such a large increase in relative displacements in August compared to May, that the vibrations do not seem larger in August. However, since the amplitudes of the signal are so much higher the impression is false. They do show larger vibration amplitudes in August. Looking at the displacement scale and comparing with the spectral densities displayed in Figures 18 and 19 it becomes evident. It is possible to see that the PRLSs vary most in amplitude in the time domain in Figure 15 compared to the SHLSs. The distance scales along the Y-axes are the same. The reason for this may be that speckle occur more on the more polished surface of the piston rod.

In August the generator is directly delta-connected to a water-cooled resistive dump load close by the WEC. This results in more cogging which can be seen in the time domain. The frequencies in August are more arbitrary than in the May measurements. It may be increased wear that explains it. This is supported by the spectral analysis in Figure 17, showing smaller peaks for the cogging and electrical circuit frequencies in August and smeared out and elevated relative intensity levels across the board in lower regions compared to the left image for May. In Figures 12 and 14 the WEC is affected by a similar wave with a similar axial force in the buoy line. The power level in August is the same as in May on the upstroke, but much lower compared to May on the down stroke, which should result in less vibration magnitudes in the WEC overall in August, when comparing Figure 16 with 17. The sensors do however detect more vibrant motion in the mechanical lead-through in August, which may be connected to wear. The vibrations themselves do have a detrimental effect on the sealing system and result in more wear. The time-frequency analyses shows more cogging and more vibrations in August, which probably comes from wear on the mechanical parts and in the mechanical-lead-through transmission.

A slight outstretched plateau is identified within the cogging bandwidth for the seal housing in the late meas- 
urements in August. The explanation is suggested to be attributed to the friction between the piston rod and the seal housing in combination with an increased play between the seal housing and piston rod. Post-experimental inspection of the sealing system in L2 indicates general wear in all direction but most prominently in the direction of the predominant incoming waves.

The PRLS and SHLS measurements support the statement that the laser sensor set-up rig is adequately stabile for measuring the relative displacement of the piston rod and seal housing. The sensors do not seem to move with the cogging frequency or the frequency would not be picked up by the sensors. There does not seem to any other common frequency for the PRLSs and SHLSs that could be attributed to an Eigen-frequency (or resonance frequency) of the set-up rig. The source of vibrations from cogging is quite far away from the location of the laser sensor set-up rig. The path is long and the possible attenuation of vibrations along the way is good enough to suggest a negligible influence on the laser sensor set-up rig. The seal housing is isolated from the capsule top plate by a rubber gasket. Any vibration transmitted from the piston rod to the seal housing would be attenuated by the dampening rubber gasket. The cogging frequencies are not transmitted through the rubber gasket and into the top plate, which can be verified but checking the data for SG 13. If for instance the sensors were to vibrate in unison with the measured objects they would have problems detecting cogging, which was not the case. The results in Figures 12-19 support the notion that the sensor set-up rig has a structural integrity with regard to the vibrations in the WEC.

Other sources of vibrations in the WEC are the frictional interface between the buoy line and the funnel at the top of the super structure and between the yoke type track rollers on the translator and inner framework. These are difficult to detect since the characteristic base frequency is unknown and might be changing all the time with translator position and speed. The rubber gasket isolates the seal housing and piston rod from being affected by vibrations emanating from the outer WEC structure, such as the funnel. The slamming of the translator against the end stops will of course generate massive vibrations but only as occasional transients. This may have implications on the choice of filter.

\section{Conclusions}

The time and frequency analysis for the different sensors show variations in content relating to the position where they are mounted. The laser triangulation sensors detect cogging frequencies and the frequency from the Lorenz forces in the stator. The strain gauges only detect the Lorenz forces.
The cogging frequencies appear within the bandwidth from 5 to $20 \mathrm{~Hz}$, varying with translator speed. The cogging is most apparent in the active AC power spectral content, as expected. The search coil sensors measuring the air gap detects the magnetic circuit frequency, which coincides with the frequency of the Lorenz forces within the stator. The vibrations from the Lorenz forces propagate through the inner framework and out through the capsule.

The spectral peaks are most prominent in May for the laser triangulation sensors. A slight plateau can be distinguished in August but the signals are contaminated by wear oriented frequencies with arbitrary spectral distribution.

The seal housing is isolated from the outer WEC structure by a rubber gasket. The vibrations from the outer structures do not propagate to the seal housing and vice versa.

The conclusion from analysis with different filters is that a moving average with a window of 21 to 51 may very well be adequate for the continued analysis of tilt angles and azimuth angles when combining the measurements from the different laser triangulation sensors.

The structural integrity of the sensor set-up has been verified on a micro measurement level and vibrations do not seem to be a problem for evaluating the performance of the piston rod mechanical lead-through.

\section{Acknowledgements}

This paper is the product of research carried out within the Lysekil project. The authors are affiliated with the Swedish Centre for Renewable Electric Energy Conversion at Uppsala University in Uppsala, Sweden. The research is supported by The Swedish Energy Agency. VINNOVA, Statkraft AS, Vattenfall AB, Fortum OY, Falkenberg Energy AB, Helukabel, Draka Cable AB, Pro Enviro, Seabased AB, The Gothenburg Energy Research Foundation, The Göran Gustavsson Research Foundation, Ångpanneföreningen's Foundation for Research and Development, The Olle Engkvist Foundation, The J. Gust. Richert Foundation, CF Environmental Fund, Vargöns Research Foundation, The Swedish Research Council grant No. 621-2009-3417 and the Wallenius Foundation. Fredrik Bülow, Kalle Haikonen and Venugoplan Kurupath are thanked for their knowledge in Matlab and for fruitful discussions.

\section{REFERENCES}

[1] A. F. de O. Falcão, "First-Generation Wave Power Plants: Current Status and R and D Requirements," Journal of Offshore Mechanics and Arctic Engineering, Vol. 126, No. 4, 2004, pp. 384-388. doi:10.1115/1.1839882

[2] J. P. Kofoed, P. Frigaard, E. Friis-Madsen and H. C. So- 
rensen, "Prototype Testing of the Wave Energy Converter Wave Dragon," Renewable Energy, Vol. 31, No. 2, 2006, pp. 181-189. doi:10.1016/j.renene.2005.09.005

[3] R. Henderson, "Design, Simulation, and Testing of a Novel Hydraulic Power Take-Off System for the Pelamis Wave Energy Converter," Renewable Energy, Vol. 31, No. 2, 2006, pp. 271-283. doi:10.1016/j.renene.2005.08.021

[4] D. Elwood, S. C. Yim, J. Prudell, C. Stillinger, A. von Jouanne, T. Brekken, A. Brown and R. Paasch, "Design, Construction, and Ocean Testing of a Taut-Moored DualBody Wave Energy Converter with a Linear Generator Power Take-Off," Renewable Energy, Vol. 35, No. 2, 2010, pp. 348-354. doi:10.1016/j.renene.2009.04.028

[5] M. Prado and H. Polinder, "Direct Drive in Wave Energy Conversion-AWS Full Scale Prototype Case Study," IEEE Power \& Energy Society General Meeting, Zijdewind, 24-29 July 2011, pp. 1-7.

[6] S. Lindroth and M. Leijon, "Offshore Wave Power Measurements-A Review," Renewable and Sustainable Energy Reviews, Vol. 15, No. 9, 2011, pp. 4274-4285. doi:10.1016/j.rser.2011.07.123

[7] M. Leijon, C. Boström, O. Danielsson, S. Gustafsson, K. Haikonen, O. Langhamer, E. Strömstedt, M. Stålberg, J. Sundberg, O. Svensson, S. Tyrberg and R. Waters, "Wave Energy from the North Sea: Experiences from the Lysekil Research Site," Surveys in Geophysics, Vol. 29, No. 3, 2008, pp. 221-240. doi:10.1007/s10712-008-9047-x

[8] R. Waters, J. Engström, J. Isberg and M. Leijon, "Wave Climate off the Swedish West Coast," Renewable Energy, Vol. 34, No. 6, 2009, pp. 1600-1606. doi:10.1016/j.renene.2008.11.016

[9] M. Rahm, C. Boström, O. Svensson, M. Grabbe, F. Bülow and M. Leijon, "Offshore Underwater Substation for Wave Energy Converter Arrays," Renewable Power Generation, IET, Vol. 4, No. 6, November 2010, pp. 602612. doi:10.1049/iet-rpg.2009.0180

[10] S. Tyrberg, H. Gravråkmo and M. Leijon, "Tracking a Wave Power Buoy Using a Network Camera-System Analysis and First Results," 28th International Conference on Ocean, Offshore and Arctic Engineering, Honolulu, 31 May-5 June 2009, pp. 799-807.

[11] S. Gustafsson, "Measuring of Waves at Islandsberg and Literature Survey of Wave Measurement Technology," Master Thesis, The Division for Electricity and Lightning Research, Uppsala University, Uppsala, 2004.

[12] O. Langhamer, D. Wilhelmsson and J. Engström, “Artificial Reef Effect and Fouling Impacts on Offshore Wave Power Foundations and Buoys-A Pilot Study," Estuarine Coastal and Shelf Science, Vol. 82, No. 3, 2009, pp. 426-432. doi:10.1016/i.ecss.2009.02.009

[13] O. Langhamer and D. Wilhelmsson, "Colonisation of Fish and Crabs of Wave Energy Foundations and the Effects of Manufactured Holes-A Field Experiment," Marine Environmental Research, Vol. 68, No. 4, 2009, pp. 151157. doi:10.1016/j.marenvres.2009.06.003

[14] C. Boström, R. Waters, E. Lejerskog, O. Svensson, M. Stålberg, E. Strömstedt and M. Leijon, "Study of a Wave Energy Converter Connected to a Nonlinear Load," IEEE Journal of Oceanic Engineering, Vol. 34, No. 2, 2009, pp.

\section{3-127. doi:10.1109/JOE.2009.2015021}

[15] O. Danielsson, M. Eriksson and M. Leijon, "Study of a Longitudinal Flux Permanent Magnet Linear Generator for Wave Energy Converters," International Journal of Energy Research, Vol. 30, No. 14, 2006, pp. 1130-1145. doi:10.1002/er.1209

[16] U. Henfridsson, V. Neimane, K. Strand, R. Kapper, H. Bernhoff, O. Danielsson, M. Leijon, J. Sundberg, K. Thorburn, E. Ericsson and K. Bergman, "Wave Energy Potential in the Baltic Sea and the Danish Part of the North Sea, with Reflections on the Skagerrak," Renewable Energy, Vol. 32, No. 12, 2007, pp. 2069-2084. doi:10.1016/j.renene.2006.10.006

[17] M. Eriksson, J. Isberg and M. Leijon, "Theory and Experiment on an Elastically Moored Cylindrical Buoy," IEEE Journal of Oceanic Engineering, Vol. 31, No. 4, 2006, pp. 959-963. doi:10.1109/JOE.2006.880387

[18] A. Savin, O. Svensson and M. Leijon, "Azimuth-Inclination Angles and Snatch Load on a Tight Mooring System," Ocean Engineering, Vol. 40, 2012, pp. 40-49. doi:10.1016/j.oceaneng.2011.12.007

[19] A. Savin, O. Svensson and M. Leijon, "Estimation of Stress in the Inner Framework Structure of a Single Heaving Buoy Wave Energy Converter," IEEE Journal of Oceanic Engineering, Vol. 37, No. 2, 2012, pp. 309-317. doi:10.1109/JOE.2012.2188614

[20] R. Waters, M. Stålberg, O. Danielsson, O. Svensson, S. Gustafsson, E. Strömstedt, M. Eriksson, J. Sundberg and M. Leijon, "Experimental Results from Sea Trials of an Offshore Wave Energy System," Applied Physics Letters, Vol. 90, No. 3, 2007, Article ID: 034105. doi:10.1063/1.2432168

[21] M. Eriksson, R. Waters, O. Svensson, J. Isberg and M. Leijon, "Wave Power Absorption: Experiments in Open Sea and Simulation," Journal of Applied Physics, Vol. 102, No. 8, 2007, Article ID: 084910. doi:10.1063/1.2801002

[22] S. Tyrberg, R. Waters and M. Leijon, "Wave Power Absorption as a Function of Water Level and Wave Height: Theory and Experiment," IEEE Journal of Oceanic Engineering, Vol. 35, No. 3, 2010, pp. 558-564. doi:10.1109/JOE.2010.2052692

[23] K. Thorburn and M. Leijon, "Farm Size Comparison with Analytical Model of Linear Generator Wave Energy Converters," Ocean Engineering, Vol. 34, No. 5, 2007, pp. 908-916. doi:10.1016/j.oceaneng.2006.05.017

[24] C. Boström, E. Lejerskog, M. Stålberg, K. Thorburn and M. Leijon, "Experimental Results of Rectification and Filtration from an Offshore Wave Energy System," Renewable Energy, Vol. 34, No. 5, 2009, pp. 1381-1387. doi:10.1016/j.renene.2008.09.010

[25] A. A. E. Price, C. J. Dent and A. R. Wallace, "Frequency Domain Techniques for Numerical and Experimental Modelling of Wave Energy Converters," 8th European Wave and Tidal Energy Conference, Uppsala, 2009, pp. 849-858.

[26] J. B. Saulnier, A. Clément, A. F. de O. Falcão, T. Pontes, M. Prevosto and P. Ricci, "Wave Groupiness and Spectral Bandwidth as Relevant Parameters for the Performance 
Assessment of Wave Energy Converters," Ocean Engineering, Vol. 38, No. 1, 2011, pp. 130-147. doi:10.1016/j.oceaneng.2010.10.002

[27] L. Yang, J. Hals and T. Moan, "Analysis of Dynamic Effects Relevant for the Wear Damage in Hydraulic Machines for Wave Energy Conversion," Ocean Engineering, Vol. 37, No. 13, 2010, pp. 1089-1102. doi:10.1016/i.oceaneng.2010.04.005

[28] O. Svensson, E. Strömstedt, A. Savin and M. Leijon, "Sensors and Measurements inside the Second and Third Wave Energy Converter at the Lysekil Research Site," 9th European Wave and Tidal Energy Conference, Southampton, 2011.

[29] O. Svensson, C. Boström, M. Rahm and M. Leijon, "Description of the Control and Measurement System Used in the Low Voltage Marine Substation at the Lysekil Research Site," 8th European Wave and Tidel Energy Conference (EWTEC), Uppsala, 2009, pp. 44-50.

[30] E. Strömstedt, O. Svensson and M. Leijon, “A Set-Up of 7 Laser Triangulation Sensors and a Draw-Wire Sensor for Measuring Relative Displacement of a Piston Rod Mechanical Lead-Through Transmission in an Offshore Wave Energy Converter on the Ocean Floor," ISRN Renewable Energy, 2012, Article ID: 746865. doi: $10.5402 / 2012 / 746865$

[31] R. Waters, O. Danielsson and M. Leijon, "Measuring Air Gap Width of Permanent Magnet Linear Generators Using Search Coil Sensor," Journal of Applied Physics, Vol. 101, No. 2, 2007, Article ID: 024518. doi:10.1063/1.2403964

[32] S. Tyrberg, O. Svensson, V. Kurupath, J. Engström, E. Strömstedt and M. Leijon, "Wave Buoy and Translator Motions-On-Site Measurements and Simulations," IEEE Journal of Oceanic Engineering, Vol. 36, No. 3, 2011, pp. 377-385. doi:10.1109/JOE.2011.2136970

[33] C. Boström, M. Rahm, O. Svensson, E. Strömstedt, A. Savin, R. Waters and M. Leijon, "Temperature Measurements in a Linear Generator and Marine Substation for Wave Power," The 29th International Conference on Ocean, Offshore and Arctic Engineering, Shanghai, 6-11
June 2010, p. 8 .

[34] I. A. Ivanova, O. Agren, H. Bernhoff and M. Leijon, "Simulation of Cogging in a $100 \mathrm{~kW}$ Permanent Magnet Octagonal Linear Generator for Ocean Wave Conversion,' 2004 International Symposium on Underwater Technology, 20-23 April 2004, pp. 345-348.

[35] I. A. Ivanova, O. Agren, H. Bernhoff and M. Leijon, "Simulation of Wave-Energy Converter with Octagonal Linear Generator," IEEE Journal of Oceanic Engineering, Vol. 30, No. 3, 2005, pp. 619-629. doi: $10.1109 /$ JOE. 2005.858373

[36] Z. Q. Zhu, P. J. Hor, D. Howe and J. Rees-Jones, "Calculation of Cogging Force in a Novel Slotted Linear Tubular Brushless Permanent Magnet Motor," IEEE Transactions on Magnetics, Vol. 33, No. 5, 1997, pp. 4098-4100. doi:10.1109/20.619675

[37] P. J. Hor, Z. Q. Zhu, D. Howe and J. Rees-Jones, "Minimization of Cogging Force in a Linear Permanent Magnet Motor," IEEE Transactions on Magnetics, Vol. 34, No. 5, 1998, pp. 3544-3547. doi:10.1109/20.717836

[38] M. F. Hsieh and K. H. Hu, "Analysis of a Tubular Linear Motor with Soft Magnetic Composites for Reciprocating Compressors," Journal of Applied Physics, Vol. 103, No. 7, 2008, Article ID: 07F112.

[39] K. Nilsson, O. Danielsson and M. Leijon, "Electromagnetic Forces in the Air Gap of a Permanent Magnet Linear Generator at No Load," Journal of Applied Physics, Vol. 99, No. 3, 2006, Article ID: 034505. doi:10.1063/1.2168235

[40] O. Danielsson, "Wave Energy Conversion," Ph.D. Thesis, Department of Engineering Sciences, Uppsala University, Uppsala, 2006.

[41] H. Herlufsen, S. Gade and H. K. Zaveri, "Analyzers and Signal Generators," In: M. J. Crocker, Ed., Handbook of Noise and Vibration Control, 2007.

[42] T. L. Harman, J. Dabney and N. Richert, "Advanced Engineering Mathematics with Matlab," 2nd Edition, Brooks/ Cole, Belmont, 2000. 